RONALD BISPO BARRETO DA SILVA

\title{
Estudo experimental em coelhos do efeito do ácido hialurônico na apoptose pós-traumática de condrócitos
}

\author{
Dissertação apresentada à Faculdade de \\ Medicina da Universidade de São Paulo para \\ obtenção do título de Mestre em Ciências \\ Programa de: Ortopedia e Traumatologia \\ Orientador: Prof. Dr. Arnaldo José Hernandez
}

São Paulo

2012 
Dados Internacionais de Catalogação na Publicação (CIP)

Preparada pela Biblioteca da

Faculdade de Medicina da Universidade de São Paulo

Creprodução autorizada pelo autor

Silva, Ronald Bispo Barreto da

Estudo experimental em coelhos do efeito do ácido hialurônico na apoptose pós-traumática de condrócitos / Ronald Bispo Barreto da Silva. -- São Paulo, 2012.

Dissertação(mestrado)--Faculdade de Medicina da Universidade de São Paulo. Programa de Ortopedia e Traumatologia.

Orientador: Arnaldo José Hernandez.

Descritores: 1.Condrócitos 2.Ácido hialurônico 3.Apoptose 4.Coelhos 5.Traumatismos do joelho 6.Joelho/anatomia \& histologia

USP/FM/DBD-019/12 
DEDICATÓRIAS 
A DEUS, por sempre iluminar meu caminho.

A minha esposa BÁRBARA (Binha), por estar a meu lado nesta trilha. Por todo o suporte e ajuda e pela paciência e dedicação. Sem Ela, finalizar esta etapa de minha vida seria muita mais difícil.

A meu PAI, pela sabedoria.

A minha MÃE, pelos exemplos vitais.

A meu irmão RICARDO, pela admiração.

A meus SOGROS, pela amizade. 
AGRADECIMENTOS 
À Dra. Márcia Uchôa de Rezende, pela idealização do projeto, pela constante motivação e incentivo e pelos ensinamentos que jamais serão esquecidos.

Aos Profs. Drs. Olavo Pires de Camargo e Arnaldo José Hernandez, pela confiança depositada.

Ao Prof. Dr. Moyses Sadigursky, pela inquestionável qualidade da análise histológica.

Aos Drs. Roberto Freire da Mota e Albuquerque e Túlio Diniz Fernandes, membros participantes da Comissão de Qualificação, pelas importantes e fundamentais correções necessárias no término desta Dissertação.

Ao Sr. Gustavo Bispo, pela amizade e por todo o trabalho dedicado ao projeto.

Às Sras. Leide Salomão, Tânia Borges e Rosana, pela atenção e cuidado aos detalhes burocráticos. 


\section{NORMALIZAÇÃO ADOTADA}

Esta dissertação de mestrado está de acordo com as seguintes normas, em vigor no momento desta publicação:

Referências: adaptado de International Committe of Medical Journals Editors (Vancouver)

Universidade de São Paulo. Faculdade de Medicina. Serviço de Biblioteca e Documentação. Guia de apresentação de dissertações, teses e monografias. Elaborado por Annelise Carneiro da Cunha, Maria Julia de A. L. Freddi, Maria F. Crestana, Marinalva de Souza Aragão, Suely Campos Cardoso e Valéria Vilhena. $3^{a}$. Ed. São Paulo: Serviço de Biblioteca e Documentação; 2011.

Abreviaturas dos títulos dos periódicos de acordo com List of Journals Indexed in Index Medicus.

Nomina anatômica (1980) do XI Congresso Internacional de Anatomia, México, 1980. 


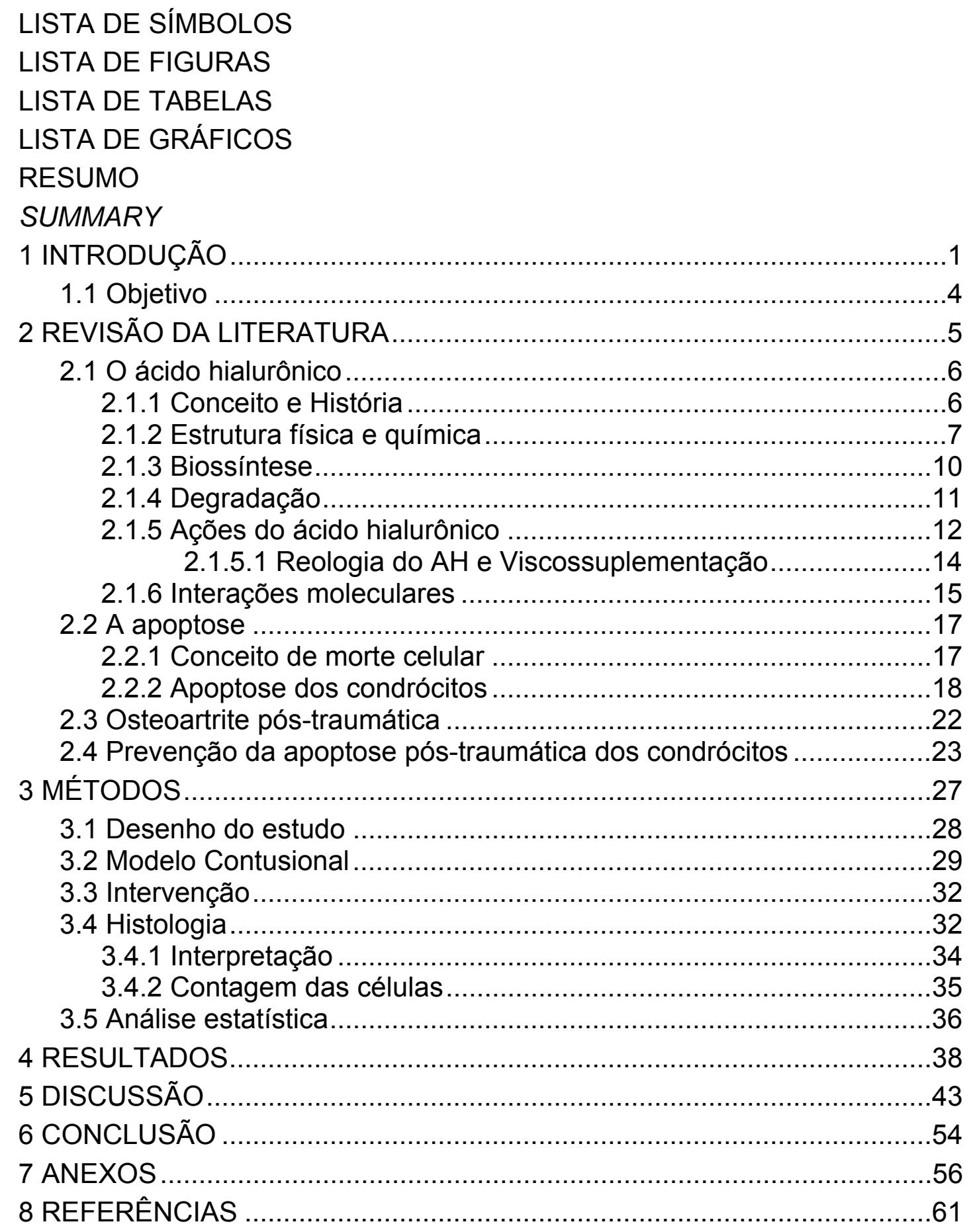


LISTAS

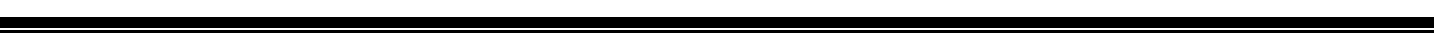




\section{SímBOLOS}

$\begin{array}{ll}\text { AH } & \text { Ácido Hialurônico } \\ \text { AVMA } & \text { American Veterinary Medical Association } \\ \text { BMP-7 } & \text { Proteína morfogênica óssea - 7 } \\ \text { cm } & \text { centímetros } \\ \text { COBEA } & \text { Colégio Brasileiro de Experimentação Animal } \\ \text { Da } & \text { Daltons } \\ \text { DNA } & \text { Ácido desoxirribonucleico } \\ \text { EGF } & \text { Fator de crescimento endotelial } \\ \text { GAG } & \text { Glicosaminoglicanos } \\ \text { HAS } & \text { Ácido Hialurônico Sintetase } \\ \text { HYAL } & \text { Hialuronidase } \\ \text { IA } & \text { Intra-articular } \\ \text { IACUC } & \text { Institute of Animal Care and Use Committee } \\ \text { IGF-I } & \text { Fator de crescimento “insulin-like" -1 } \\ \text { IL-1 } & \text { Interleucina - 1 } \\ \text { IL-4 } & \text { Interleucina - 4 } \\ \text { ISOL } & \text { ligação in situ de oligonucleotídeo } \\ \text { kg } & \text { quilograma } \\ \text { LCA } & \text { Ligamento Cruzado Anterior } \\ \text { LIM 41 } & \text { Laboratório de Investigação Médica - 41 } \\ \text { MEC } & \text { Matriz Extracelular } \\ \text { mg } & \text { miligrama } \\ \text { ml } & \text { mililitros } \\ \text { MMP } & \text { Metaloproteinases da matriz } \\ \text { NaCl } & \text { Cloreto de Sódio } \\ \text { NO } & \text { Óxido Nítrico } \\ \text { OP-1 } & \text { Proteína osteogênica-1 } \\ \text { PBS } & \text { Salina tamponada com fosfato } \\ & \end{array}$




$\begin{array}{ll}\text { PDGF } & \text { Fator de crescimento derivado das plaquetas } \\ \text { PGE2 } & \text { prostaglandinas E2 } \\ \text { ssDNA } & \text { análise da desnaturação do DNA } \\ \text { TGF-b } & \text { Fator de Necrose Tumoral - beta } \\ \text { TNF } & \text { Fator de Necrose Tumoral } \\ \text { TNF-a } & \text { Fator de Necrose Tumoral - alfa } \\ \mu L & \text { microlitros } \\ \mu \mathrm{M} & \text { micrômetros }\end{array}$




\section{FIGURAS}

Figura 1 - Desenho esquemático da estrutura química do ácido hialurônico. (S1) ácido D-glicurônico e (S2) N-acetil-

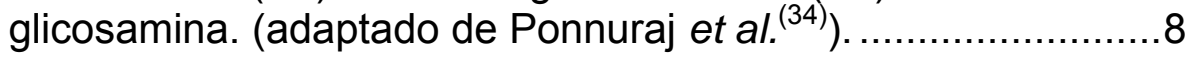

Figura 2 - Desenho esquemático da estrutura da matriz extracelular da cartilagem hialina (adaptado de Moreland ${ }^{(39)}$ ).

Figura 3 - Diagrama esquemático do papel de vários fatores que induzem a apoptose do condrócito (adaptado de Aiger et al. $\left.{ }^{(69)}\right)$.

Figura 4 - Preparação do coelho para a contusão no joelho esquerdo.

Figura 5 - Contusão no joelho esquerdo

Figura 6 - Hiperemia reacional pós-contusão.

Figura 7 - Fotografia da coleta do material para a histologia. No detalhe: o joelho direito encontra-se em flexão de $90^{\circ}$, com a patela luxada lateralmente. Cartilagem da tróclea femoral, sendo dissecada pela lâmina de bisturi (seta cheia em branco) e côndilo femoral lateral (seta cheia em preto).

Figura 8 - $\quad$ Micrografia da lâmina preparada pela técnica de TUNEL (aumento de 400x), mostrando núcleos de condrócitos corados em azul escuro (células viáveis, seta cheia em azul), núcleos corados em castanho (núcleos em apoptose, seta pontilhada) e condroplastos (espaços vazios, setas cheias em branco). 


\section{TABELAS}

Tabela 1 - Descrição dos pesos dos coelhos e dos percentuais de apoptose e resultado dos testes comparativos

Tabela 2 - Resultado das correlações de Pearson entre as diferenças no percentual de apoptose e alteração no peso e total de células analisadas. 


\section{GRÁFICOS}

Gráfico 1 - Percentuais médios de apoptose em cada joelho e respectivos erros-padrões.

Gráfico 2 - Diagrama de dispersão entre a diferença no percentual de apoptose e a alteração no peso.

Gráfico 3 - Diagrama de dispersão entre a diferença no percentual de apoptose e o total de células. 
RESUMO 
Silva RBB. Estudo experimental em coelhos do efeito do ácido hialurônico na apoptose pós-traumática de condrócitos [Dissertação]. São Paulo: Faculdade de Medicina, Universidade de São Paulo; 2012. 76 p.

O objetivo deste estudo foi avaliar se a injeção intra-articular em altas doses de ácido hialurônico, imediatamente após o trauma, pode reduzir a apoptose de condrócitos. Para cumprir este objetivo foi desenvolvido um estudo experimental com 40 joelhos de coelhos adultos. Os animais foram anestesiados e, em seguida, cada joelho sofreu três contusões com um bloco de $1 \mathrm{~kg}$, solto por meio de um cilindro, a 1 metro de altura. Logo após as contusões, foram administrados, no mesmo coelho, $2 \mathrm{ml}$ de ácido hialurônico em um joelho e $2 \mathrm{ml}$ de solução salina no outro. Desta forma, obteve-se uma intervenção pareada, com melhora do poder estatístico do estudo. As doses foram repetidas a cada 3 ou 4 dias por 30 dias. Os coelhos foram mantidos no mesmo ambiente sob controle de temperatura, de atividades diárias e de alimentação. Após 30 dias, os animais foram abatidos e, por meio de artrotomia, foram realizadas as coletas da cartilagem do côndilo femoral medial e da tróclea de cada joelho. As peças foram preparadas para análise em microscopia óptica e coloração por TUNEL. Os indivíduos envolvidos no preparo e análise das peças não tiveram qualquer tipo de informação a respeito do experimento. A análise estatística foi feita pelo Teste t-student para dados pareados na comparação entre o grupo ácido hialurônico (AH) e o grupo controle. Foram analisados um total de 36 joelhos e obteve-se uma redução significativa $(p<0,001)$ na taxa de apoptose de $68,01 \%( \pm 19,73)$ do grupo controle para $53,52 \%( \pm 18,09)$ do grupo $\mathrm{AH}$. Diante dos resultados, concluiu-se que a injeção intra-articular de altas doses de ácido hialurônico, iniciando imediatamente após o trauma, reduz as taxas de apoptose (pós-traumática) de condrócitos de coelhos.

Descritores: 1. Condrócitos 2. Ácido Hialurônico 3. Apoptose 4. Coelhos 5. Traumatismo do joelho 6. Joelho / anatomia \& histologia 
SUMMARY 
Silva RBB. Rabbit experimental-study of hyaluronic acid effect on chondrocyte impact-induced apoptosis [Dissertation]. São Paulo: "Faculdade de Medicina, Universidade de São Paulo"; 2012. 76 p.

The aim of this study was to assess whether intra-articular injection of high doses of hyaluronic acid immediately after trauma, can reduce apoptosis of chondrocytes. We have developed an experimental study with forty knees of adult rabbits. Animals were anesthetized and each one had had three knee injuries with a block of $1 \mathrm{~kg}$, released through a cylinder, 1 meter tall. After the bruises, $2 \mathrm{ml}$ of hyaluronic acid were injected in one knee and $2 \mathrm{ml}$ saline in the other. Doses were repeated each 3 or 4 days during 30 days. Rabbits were kept in the same environment under controlled temperature, daily activities and meals. Thirty days later, animals have been sacrificed. The cartilage of the medial femoral condyle and trochlea of each knee was retrieved with a scalpel by artrothomy. Specimens were prepared for optical microscopy and TUNEL staining. No information about the experiment was given to individuals who were involved in the preparation and analysis of the slides. Statistical analysis was performed by Student's $t$ test for paired data when comparing a group of hyaluronic acid (HA) and control group. We have analyzed a total of 36 knees and have obtained a significant reduction $(p<0.001)$ in apoptosis rate of $68.01 \%( \pm 19.73)$ for the control group 53.52\% $( \pm 18.09)$ in the HA group. We conclude that the intraarticular injection of high doses of hyaluronic acid starting immediately after trauma, reduces impact-induced chondrocytes' apoptosis rates in rabbit's.

Descriptors: 1. Chondrocytes 2. Hyaluronic Acid 3. Apoptosis 4. Rabbits 5. Knee Traumatism 6. Knee / anatomy \& histology 
1 INTRODUÇÃO 
A cartilagem articular possui uma capacidade reparativa limitada, mas as razões para isso não são completamente compreendidas ${ }^{(1,2)}$. Embora vários estudos histológicos demonstrem a ocorrência de morte dos condrócitos em resposta ao trauma, é só agora que está sendo estabelecido se a morte celular ocorre por apoptose ou por necrose ${ }^{(3-5)}$.

A apoptose tem sido estudada em outros tecidos e células. Vários indutores de apoptose foram identificados, incluindo agentes químicos, citocinas, patógenos virais, bacterianos e lesões térmicas ${ }^{(6-9)}$. A apoptose também pode ser decorrente de estresse mecânico em uma variedade de células $^{(10-12)}$. É um processo de morte celular de regulação evolutiva que desempenha um papel essencial no desenvolvimento embrionário e no "turnover" celular fisiológico(13).

A apoptose do condrócito ocorre na artrose e na resposta à lesão mecânica em estudos in vitro ${ }^{(14-16)}$. Estes estudos concluíram que o início da apoptose do condrócito pode ser um dos eventos mais precoces em resposta à lesão mecânica. Murray et al. ${ }^{(17)}$ demonstraram uma taxa de $35 \%$ de morte de condrócitos nos fragmentos osteocondrais retirados após fraturas intra-articulares em humanos. A taxa encontrada é mais que o dobro das verificadas nos joelhos com artrose (15\%). Os índices elevados de apoptose observados ajudam a explicar a ocorrência de artrose póstraumática, mesmo após a obtenção da redução anatômica da fratura. 
Para o tratamento de defeitos condrais em articulações sinoviais, Salter RB et al. ${ }^{(18,19)}$ avaliaram o efeito benéfico da movimentação passiva contínua, em comparação com a imobilização articular, no reparo da cartilagem hialina, demonstrando ser não apenas mais rápido, como mais completo.

Colwell et al. ${ }^{(20)}$ demonstram que a prevenção da artrose póstraumática está diretamente relacionada com a prevenção da apoptose celular. Outros trabalhos mostram que o bloqueio da apoptose por agentes medicamentosos diminuem a morte celular e aumentam a sobrevida. Alguns destes agentes são os inibidores das caspases (proteases específicas do aspartato dependentes de cisteína) ${ }^{(21)}$, glicosamina ${ }^{(22)}$, diacereína ${ }^{(23)}$ e proteína osteogênica-1 (OP-1) ${ }^{(24)}$.

Shikhman et al. ${ }^{(22)}$ observam que a injeção intra-articular (IA) de glicosamina em coelhos, apresenta um efeito condroprotetor, com a diminuição da degradação da cartilagem articular e supressão da sinovite. Outros autores compararam a administração IA de Glicosamina (Dglicosamina) e seu derivado, peptidil-glicosamina, em coelhos, obtendo um efeito estrutural benéfico anticatabólico e anti-inflamatório no condrócitos ${ }^{(25)}$.

Echigo et al. ${ }^{(26)}$ demonstram que a injeção $\mathrm{IA}$ de $\mathrm{AH}$ suprime a apoptose de condrócitos induzidas por impacto. Entretanto, estes autores iniciaram o tratamento 7 dias depois da contusão. Por outro lado, D'Lima et al. ${ }^{(27)}$ mostram o aumento progressivo de células apoptóticas iniciando 6 horas após o trauma, oferecendo uma janela terapêutica potencial nas 6 primeiras horas de lesão. Mazières et al. ${ }^{(23)}$, com um modelo contusional em 
coelhos, sugeriram uma modulação medicamentosa (profilática) da apoptose pós-traumática, com a administração imediata após a contusão, de diacereína. Seguindo a mesma linha de raciocínio, Rezende et al. ${ }^{(28)}$ demonstram que a aplicação de plasma rico em plaquetas (PRP), imediatamente após a lesão, reduz a taxa de apoptose da cartilagem de coelhos.

\subsection{OBJETIVO}

Avaliar o efeito supressor da injeção intra-articular de ácido hialurônico no processo de apoptose dos condrócitos, aplicada imediatamente após a contusão dos joelhos de coelhos. 
2 REVISÃO DA LITERATURA 


\subsection{O ÁCIDO HIALURÔNICO}

\subsubsection{CONCEITO E HISTÓRIA}

Em 1934, Karl Meyer e seu colega John Palmer isolaram uma substância química, até então desconhecida, do corpo vítreo de olhos de vaca. A substância encontrada continha duas moléculas de açúcar, uma das quais era o ácido urônico. Para sua conveniência, propuseram o nome de "ácido hialurônico" (AH). O nome popular é derivado de "Hyalos", que é a palavra grega para o vidro + ácido urônico, (Meyer e Palmer, 1934) apud Necas et al. ${ }^{(29)} \mathrm{Na}$ época, eles não sabiam que a substância descoberta iria se revelar como uma das mais interessantes e úteis macromoléculas naturais.

A primeira aplicação médica do $\mathrm{AH}$ em humanos foi como substituição/reposição do vítreo durante uma cirurgia oftalmológica no final dos anos de 1950. O AH foi isolado inicialmente nos cordões umbilicais de humanos e pouco depois, na crista de galo, em uma forma altamente purificada e de peso molecular elevado. Sabe-se agora que o AH é

* Meyer K, Palmer FW. The polysaccharide of the vitreous humor. J Biol Chem. 1934;107: 629-34 
encontrado em todo o espaço extracelular dos grandes animais, com sua maior concentração dentro do tecido conjuntivo frouxo ${ }^{(30)}$.

A estrutura química do hialuronano foi descrita por Karl Meyer e seus colaboradores em 1958. Pela primeira vez, foi isolado como um ácido, mas, sob condições fisiológicas, comportou-se como um sal (hialuronato de sódio) $)^{(31)}$.

O termo "ácido hialurônico" foi introduzido em 1986 para se conformar com a nomenclatura internacional dos polissacarídeos e é atribuído a Endre Balazs $^{(32)}$, que cunhou este nome para abranger as diferentes formas que a molécula pode tomar: a forma ácida, como o ácido hialurônico, e os sais, tais como o hialuronato de sódio, que formam a nível $\mathrm{pH}$ fisiológico ${ }^{(30,33)}$.

\subsubsection{ESTRUTURA FÍSICA E QUÍMICA}

A estrutura do $\mathrm{AH}$ determinada por Meyer $^{(31)}$ ocorreu por meio de métodos químicos e enzimáticos. É descrito como um polímero linear de dissacarídeos compostos por unidades alternadas de ácido $D$-glicurônico e $N$-acetil-glicosamina (Figura 1), ligadas entre si por meio de ligações glicosídicas $\beta 1,4$ e $\beta 1,3$. O ácido $D$-glicurônico recebe este nome após a modificação da molécula de glicose, no qual o radical $\left(-\mathrm{CH}_{2} \mathrm{OH}\right)$ é substituído pela terminação ácido carboxílico $(-\mathrm{COOH})$. A outra metade do $\mathrm{AH}$, formada pela $\mathrm{N}$-acetil-glicosamina - glicose com um radical amina $\left(-\mathrm{NH}_{2}\right)$, é chamada 
glicosamina. Esta apresenta um radical acetil $\left(\mathrm{CH}_{3}-\mathrm{CO}-\right)$ ligado ao nitrogênio (N) da amina e recebe o nome de $N$-acetil-glicosamina.

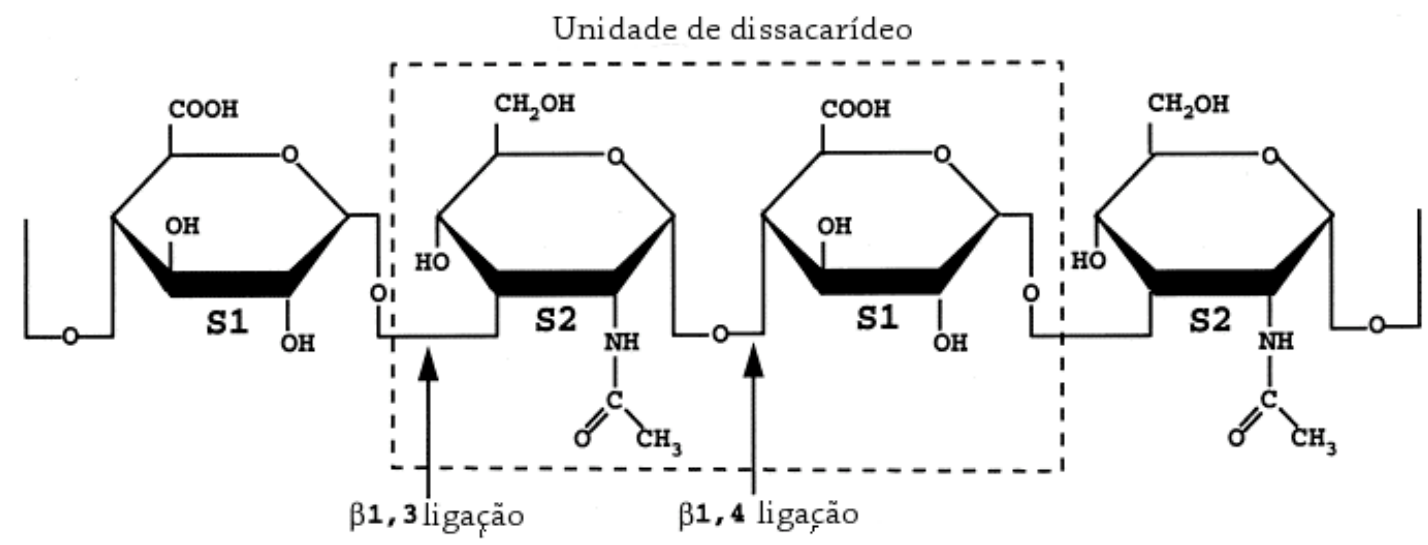

Figura 1 - Desenho esquemático da estrutura química do ácido hialurônico. (S1) ácido D-glicurônico e (S2) N-acetilglicosamina (adaptado de Ponnuraj et al. ${ }^{(34)}$ )

Do ponto de vista bioquímico, o AH é classificado dentro do grupo dos glicosaminoglicanos (GAG's) pois um de seus açúcares estruturais é modificado por uma terminação amina. Por sua vez, os GAG's fazem parte do subgrupo dos polissacarídeos e estes, dos carboidratos ${ }^{(35)}$.

A molécula do $\mathrm{AH}$ composta pela repetição indefinida de unidades de dissacarídeos pode atingir um peso molecular que varia entre $10^{4}$ e $10^{7} \mathrm{Da}$. Está presente em grande quantidade dentro alguns tecidos (crista de galo, humor vítreo e cartilagem) e desempenha desde tarefas mecânicas muito simples, como preenchimento espacial na matriz e lubrificação nas articulações sinoviais, até fazer parte de importantes processos fisiológicos específicos da superfície celular, como interação bioquímica intercelular ${ }^{(36)}$. 
Suas propriedades físicas e físico-químicas são determinadas por sua massa molecular e conformação espacial. As moléculas de alto peso molecular de AH se entrelaçam, formando uma solução de alta viscosidade com propriedades importantes para o fluido sinovial. Desta forma, o AH pode servir tanto como um lubrificante eficaz nas articulações quando estas são movimentadas lentamente, como um amortecedor de choques para movimentos bruscos ${ }^{(37)}$.

Outra propriedade importante do $\mathrm{AH}$ é sua capacidade de fornecer suporte estrutural a alguns tecidos orgânicos, sobretudo da cartilagem hialina que é um dos componentes mais comuns. Na matriz extracelular (MEC) da cartilagem (Figura 2), o AH agrupa-se com outras moléculas grandes chamadas de agrecanos (um tipo específico de proteoglicano). Estas se ligam ao $\mathrm{AH}$ como "cerdas de uma escova de garrafa". Cada uma destas "cerdas" é um proteoglicano, ou seja, GAG's ligados a uma proteína linear. Neste caso, os GAG's são dois: 1. sulfato de condroitina, pequena variação do ácido hialurônico que utiliza N-acetil-galactosamina-4-sulfato no lugar do $\mathrm{N}$-acetil-glicosamina do $\mathrm{AH}$; e 2. sulfato de queratina ${ }^{(37-39)}$. 


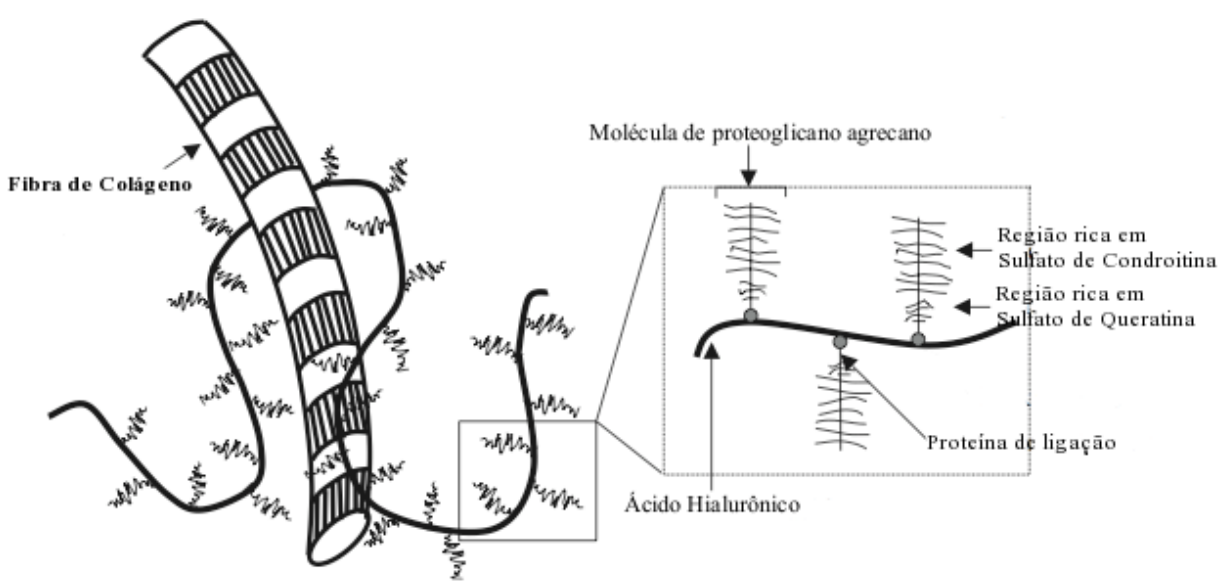

Figura 2 - Desenho esquemático da estrutura da matriz extracelular da cartilagem hialina (adaptado de Moreland ${ }^{(39)}$ )

\subsubsection{BIOSSÍNTESE}

As moléculas de $\mathrm{AH}$ são sintetizadas na membrana plasmática por proteínas integradas à membrana chamadas hialuronano sintetases. Os mamíferos possuem três tipos destas proteínas: HAS-1, HAS-2 e HAS-3 ${ }^{(40)}$. Estas enzimas alongam o $\mathrm{AH}$ por meio do acréscimo repetitivo de ácido glicurônico e $\mathrm{N}$-acetil-glicosamina ao polissacarídeo produzido. À medida que é sintetizado, o $\mathrm{AH}$ é extraído via transportador-ABC por meio da membrana plasmática para o espaço extracelular ${ }^{(41)}$.

Conforme citam Laurent e Fraser ${ }^{(30)}$, este processo de biossíntese do $\mathrm{AH}$ é estimulado por alguns fatores conhecidos, como EGF, PDGF, TGF $\beta$, IGF-I e IL-4, que ativam a síntese molecular. Os autores também destacam que quase todos os tipos de células dos vertebrados sintetizam o $\mathrm{AH}$. No entanto, é a linhagem celular mesodérmica que se apresenta de forma mais 
ativa. Por outro lado, Nakazawa et al. ${ }^{(42)}$ mostraram que a síntese do $\mathrm{AH}$ pode ser inibida pelo 4-metillumbeliferona, um derivado cumarínico. Esta inibição seletiva (sem inibir outros GAG's) pode ser útil na prevenção da metástase de células tumorais.

São descritos três tipos de produção do $A H^{(43)}$ : 1. Extração do $A H$ a partir de matéria-prima animal (cordão umbilical, crista de galo): neste processo, consegue-se $\mathrm{AH}$ de alto peso molecular (aprox. $5 \times 10^{6} \mathrm{Da}$ ); 2 . Biofermentação, que inclui as etapas de fermentação, extração e de purificação e utiliza determinadas cepas de Streptococcus produzindo $\mathrm{AH}$ com peso molecular de até $2,5 \times 10^{6} \mathrm{Da}$; 3. produção sintética (cross-linked) de $A H$, que não usa matéria de origem animal nem solventes orgânicos. Neste, consegue-se $\mathrm{AH}$ com peso molecular entre 1,8 e $12,5 \times 10^{6}$.

\subsubsection{DEGRADAÇÃO}

Os processos de anabolismo e catabolismo do AH são essenciais para a manutenção tecidual e exercem uma importante função na estruturação da cartilagem. $\mathrm{O}$ catabolismo do $\mathrm{AH}$ na cartilagem é regulado por uma família de enzimas chamadas hialuronidases (HYALs) que degradam o $\mathrm{AH}$ em pequenos fragmentos. Estes produtos da degradação do $\mathrm{AH}$ são oligossacarídeos e $\mathrm{AH}$ de peso molecular muito baixo que possuem propriedades pró-angiogênicas e pró-inflamatórias ${ }^{(44-46)}$. 
Carga mecânica é um importante regulador da atividade metabólica dos condrócitos. Alterações na amplitude e frequência da carga podem ter um efeito significativo sobre a produção de macromoléculas da MEC e dos principais agentes de degradação da cartilagem ${ }^{(47)}$. Uma carga excessiva pode resultar na degradação da cartilagem por meio de diversos mecanismos. Tanimoto et al. ${ }^{(48)}$ descrevem um mecanismo no qual a sobrecarga mecânica aumenta a produção de IL-1 $\beta$ e TNF- $\alpha$. Na presença destas citocinas, os condrócitos aumentam a expressão de HYAL1 e HYAL2, resultando no catabolismo do AH na cartilagem articular.

Outro mecanismo importante de degradação do $\mathrm{AH}$ ocorre por meio da ação de hialuronidases produzidas por certos tipos de bactérias, como o Staphylococcus aureus, Streptococcus pyogenes et pneumoniae e Clostridium perfringens. Este mecanismo aumenta sua mobilidade por meio dos tecidos corporais e seu disfarce antigênico que evita o reconhecimento pelos fagócitos e sistema imune ${ }^{(34)}$.

\subsubsection{AÇÕES DO ÁCIDO HIALURÔNICO}

Embora o mecanismo predominante do $\mathrm{AH}$ seja desconhecido, in vivo e in vitro, estudos clínicos demonstram diferentes efeitos fisiológicos do AH exógeno ${ }^{(39)}$.

O ácido hialurônico possui um número de funções físico-químicas protetoras que podem apresentar alguns efeitos adicionais condroprotetores 
in vivo e podem explicar seus efeitos a longo prazo sobre a cartilagem $\operatorname{articular}^{(49)}$. O AH pode reduzir os impulsos nervosos e a sensibilidade do nervo associado à dor ${ }^{(50)}$. Na osteoartrite experimental, este GAG foi incorporado pela cartilagem e obteve efeito de preservação do fenótipo dos condrócitos e estímulo para proliferação e síntese da $M E C^{(51)}$.

$\mathrm{O} A \mathrm{H}$ exógeno aumenta o $\mathrm{AH}$ dos condrócitos e aumenta a síntese de proteoglicanos, reduz a produção e a atividade de mediadores próinflamatórios e das metaloproteinases da MEC. Também altera o comportamento das células do sistema imunológico por meio da inibição da adesão dos complexos imunes aos polimorfonucleares, da inibição da migração de macrófagos e leucócitos e pela agregação e proliferação dos fibroblastos $^{(52)}$.

$\mathrm{O} \mathrm{AH}$ possui uma alta resistência aos fluxos de água, podendo agir como uma barreira contra alterações rápidas do conteúdo aquoso. Uma solução de $\mathrm{AH}$ tem pressão osmótica não ideal, ou seja, com o aumento da concentração do $\mathrm{AH}$ na solução, ocorre aumento exponencial de sua pressão osmótica. Isso fornece à solução de $\mathrm{AH}$ uma capacidade de tamponamento osmótico, útil na regulação do conteúdo de água nos tecidos $^{(53)}$.

Além de sua função como uma molécula estrutural, o ácido hialurônico também atua como uma molécula sinalizadora, interagindo com receptores químicos. Isto resulta em ativação de cascatas que influenciam a migração celular, proliferação e diferenciação e expressão protéica ${ }^{(54)}$. Além 
disso, o AH é essencial para o desenvolvimento embrionário e exerce papel importante na progressão tumoral ${ }^{(55,56)}$.

\subsubsection{Reologia do AH e Viscossuplementação}

A viscossuplementação é o processo terapêutico pelo qual o estado reológico normal de um compartimento é restaurado ou melhorado pela introdução do $\mathrm{AH}$ exógeno. A viscoelasticidade do fluido sinovial da articulação é determinado pelo conteúdo de $\mathrm{AH}$ e, por sua vez, as propriedades viscoelásticas do líquido sinovial refletem as propriedades reológicas das estruturas intercelulares da articulação (película brilhante "Lamina Splendens" do latim, tecido sinovial, cápsula, ligamentos intraarticulares) $)^{(52)}$.

$\mathrm{Na}$ artrose, a elasticidade e a viscosidade do líquido sinovial são muito menores que a da articulação normal. As causas desta redução nas propriedades reológicas são tanto pela presença de pequenas moléculas de AH como pela baixa concentração de $\mathrm{AH}$. O estresse mecânico causado pelo movimento da articulação determina a ocorrência de fibrilação e alteração da rede de colágeno da cartilagem superficial e do tecido sinovial. Além disso, o movimento causa dobras e alongamentos constantes da membrana sinovial, resultando na morte das células produtoras de $\mathrm{AH}$. Pela redução na quantidade de $\mathrm{AH}$ intra-articular, receptores da dor são induzidos mecanicamente, pois ficam desprotegidos em razão da perda do efeito de absorção de impacto do $\mathrm{AH}^{(52)}$. 
A viscossuplementação restaura o ambiente reológico normal da rede de fibras de colágeno e celular, promovendo a proteção imediata e o efeito de absorção de impacto, sugerindo, desta forma, ser benéfica na patologia das articulações ${ }^{(52)}$.

\subsubsection{INTERAÇÕES MOLECULARES}

$\mathrm{O} \mathrm{AH}$ desempenha diversas funções organizacionais da MEC por meio da comunicação molecular com as células e outros componentes da matriz. Após se estabeler a sequência de aminoácidos no $\mathrm{AH}$ da região de ligação de agrecano e da proteína de ligação(57), o número de relatos de proteínas/receptores específicos de $\mathrm{AH}$ é crescente. Assim, o $\mathrm{AH}$ interage com diversos receptores de superfície celular como o CD44, Receptor de AH Mediador da Mobilidade (RHAMM), Receptor $\mathrm{AH}$ do Endotélio de Vaso Linfático (LYVE-1), Receptor de AH para Endocitose (HARE), Receptor hepático de depuração celular e endotelial e Receptor Toll-like 4. Destes, o CD44 e o RHAMM são os mais conhecidos, pois são receptores associados à transdução de sinais que influenciam a sobrevivência, proliferação e motilidade celular. Além disso, são conhecidos por estarem intimamente ligados à metástase de tumores ${ }^{(54,58-60)}$.

O CD44 é uma glicoproteína de superfície celular, estruturalmente variável e multifuncional, que está presente na maioria dos tipos celulares ${ }^{(61)}$. É considerado o principal receptor de ácido hialurônico por sua ampla 
distribuição, sendo, também, o mais estudado ${ }^{(62,63)}$. A interação do CD44 com o $\mathrm{AH}$ está envolvida em várias funções da biologia celular, como adesão, migração, invasão e mobilidade celular, além de degradação do MEC mediada por metaloproteinases e crescimento de células tumorais ${ }^{(64)}$.

O RHAMM foi encontrado tanto na superfície como no citosol e no núcleo celular ${ }^{(63,65)}$. Está envolvido na regulação da resposta celular a fatores de crescimento e desempenha um papel importante na migração celular, sobretudo para fibroblastos e células lisas (vascular, muscular e nervosa) ${ }^{(58)}$.

Os fragmentos pequenos de $\mathrm{AH}$ e os $\mathrm{AH}$ de baixo e médio peso molecular $\left(2 \times 10^{4}\right.$ a $\left.4,5 \times 10^{5} \mathrm{Da}\right)$ estimulam a expressão gênica de macrófagos, de células endoteliais, de eosinófilos e de algumas células epiteliais $^{(66,67)}$ e contribuem para a formação de tecido cicatricial. Nos ferimentos de fetos que curam sem deixar cicatrizes, o fluido de $\mathrm{AH}$ de alto peso molecular está presente; no entanto, quando a hialuronidase é adicionada para gerar fragmentos menores de HA, há aumento da formação de cicatrizes. Esses dados apoiam a teoria de que $\mathrm{AH}$ de alto peso molecular promove quiescência celular e auxilia na manutenção da integridade dos tecidos. Por outro lado, os produtos da degradação do $\mathrm{AH}$ são um sinal de que uma lesão ocorreu, dando início à resposta inflamatória tecidual $^{(68)}$. 


\subsection{A APOPTOSE}

\subsubsection{CONCEITOS DE MORTE CELULAR}

Rigorosamente falando, necrose engloba todas as formas de morte celular programada e não programada. Geralmente, o termo necrose é usado para a morte celular não programada, enquanto apoptose é o termo empregado para a morte celular "programada"(69).

A apoptose foi descrita inicialmente como uma forma específica de morte celular, envolve uma série de eventos celulares programados, alguns dos quais são morfologicamente identificáveis. Para que a morte celular seja classificada como apoptótica, deve-se observar a presença de condensação e fragmentação da cromatina nuclear, além de quebra cromossomal do DNA e formação de corpos apoptóticos contendo fragmentos de célula morta e membrana plasmática íntegra ${ }^{(70,71)}$.

A necrose é caracterizada morfologicamente pela vacuolização do citoplasma, degradação da membrana plasmática e pela indução da inflamação em torno da célula morta. Isso é atribuível à liberação do conteúdo celular e das moléculas pró-inflamatórias. As células que morrem por necrose frequentemente apresentam alterações na morfologia nuclear, mas não a condensação da cromatina organizada e fragmentação de DNA características da apoptose ${ }^{(71)}$. 
A apoptose é considerada um importante mecanismo pelo qual o organismo remove as células que não estão funcionando corretamente ou não mais exercem a função determinada para o estágio de desenvolvimento tecidual.

A apoptose representa um processo biomolecular complexo, com duas principais vias de sinalização: a intrínseca e a extrínseca. Existe uma enorme variedade de sinais apoptóticos, incluindo privação do fator de crescimento, hipóxia, estresse oxidativo e dano ao DNA, que ativam a via intrínseca. Por outro lado, a via extrínseca é ativada quando ligantes de morte, como o fator de necrose tumoral-a, ligam-se a receptores na membrana plasmática e seus domínios intracelulares recrutam e ativam uma cascata de caspases. Por fim, estas enzimas atingem, direta ou indiretamente, a mitocôndria resultando na morte celular ${ }^{(72)}$.

\subsubsection{APOPTOSE DOS CONDRÓCITOS}

A apoptose dos condrócitos tem sido reconhecida por desempenhar um importante papel na destruição da cartilagem ${ }^{(73)}$. Hashimoto et al. ${ }^{(74)}$ descreveram a relação entre a apoptose de condrócitos e a degradação da cartilagem. A apoptose possui este efeito degenerativo condral em razão da permanência dos produtos "pós-apoptóticos", como o pirofosfato e cristais de cálcio, que não são efetivamente removidos da cartilagem ${ }^{(75)}$. Além disso, 
durante o processo de apoptose, ocorre a formação de "corpos apoptóticos" contendo enzimas que degradam a $\mathrm{MEC}^{(76)}$.

Células apoptóticas foram encontradas nas camadas superficiais e médias da cartilagem articular de humanos com artrose ${ }^{(74)}$. Por outro lado, na cartilagem normal o número de células apoptóticas detectadas é pequeno, localizadas apenas nas camadas superficiais ou dentro de clones de condrócitos em proliferação ${ }^{(73)}$.

Os condrócitos são conduzidos à apoptose em resposta a diversos estímulos (Figura 3), incluindo perda da adesão celular ${ }^{(77)}$ em resposta ao ligante $\mathrm{Fas}^{(78)}$, Óxido Nítrico $(\mathrm{NO})^{(79)}$, estaurosporina/diidrocitocalasina $\mathrm{B}^{(80)}$, ceramida e ácido retinóico $^{(81)}$ e estímulo mecânico ${ }^{(1)}$.

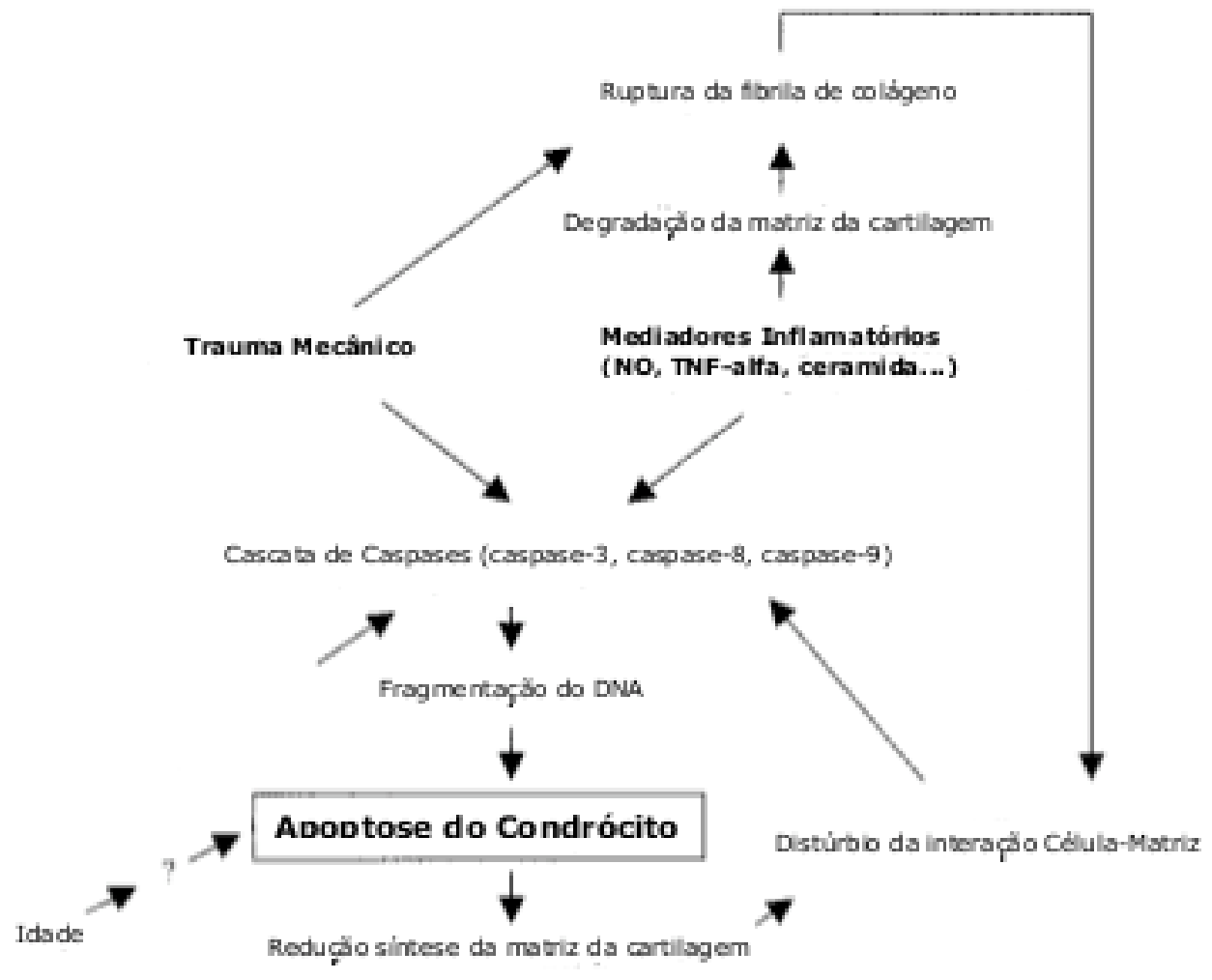

Figura 3 - Diagrama esquemático do papel de vários fatores que induzem a apoptose do condrócito. (adaptado de Aiger et al. ${ }^{(69)}$ ) 
Ishizaki et al. ${ }^{(77)}$ relatam que a maioria das células requer comunicação intercelular para sobreviver e, na cartilagem, isso não é diferente. Os condrócitos produzem fatores que promovem a própria sobrevivência celular, atuando de forma autócrina ou parácrina. Conforme Werb et al. ${ }^{(82)}$, a indução da apoptose ocorre após a perda da interação do condrócito com a MEC, mecanismo típico das células aderentes, demonstrado em diversos sistemas celulares ${ }^{(83)}$.

Para Yang et al. ${ }^{(84)}$, existem evidências indiretas de que o colágeno tipo II influencia a sobrevivência dos condrócitos. Na ausência de colágeno II, os condrócitos apresentam núcleo condensado e fragmentação do DNA nuclear característicos da morte celular por apoptose.

Kuhn et al. ${ }^{(78)}$ descrevem o ligante Fas (FasL ou CD95) como sendo uma forma de proteína transmembrana tipo II, da mesma família dos TNF, que é encontrada nos condrócitos localizados na zona superficial da cartilagem. Para Hashimoto et al. ${ }^{(85)}$, a ativação do receptor do ligante Fas desencadeia o processo de apoptose dos condrócitos. Ainda não se sabe em que condições os condrócitos expressam o Fas; no entanto, as únicas fontes do ligante Fas, descritas na articulação, são as células inflamatórias do tecido e líquido sinovial ${ }^{(73)}$. Aigner et al. ${ }^{(69)}$ destacam a importância da apoptose dos condrócitos mediada pelos receptores de Fas, pois esta via apoptótica apresenta potencial terapêutico nas sinovites da artrite reumatoide.

Hashimoto et al. ${ }^{(12)}$ relacionam a ocorrência de apoptose com a produção aumentada de NO. Nesta via apoptótica, os condrócitos 
estimulados pela presença de determinadas citocinas (IL-1 e TNF) secretam grande quantidade de NO. Conforme Miwa et al. ${ }^{(86)}$, sob tal estímulo, a célula aumenta a expressão de cicloxigenaxe 2 e esta, por sua vez, aumenta a secreção de prostaglandinas $E_{2}\left(P E_{2}\right)$. A PGE 2 induz a fragmentação do DNA, direta ou indiretamente. Blanco et al. ${ }^{(79)}$ relatam que a quantidade aumentada de NO, além de ser um potente estimulador da apoptose de condrócitos, inibe a síntese de macromoléculas da MEC como o agrecano, e aumenta a atividade das metaloproteinases da matriz (MMP). Desta forma, o NO torna-se um importante agente promotor da degradação condral.

Loening et al. ${ }^{(87)}$ demonstram que a apoptose de condrócitos pode ser induzida por carga compressiva em cartilagem de bovinos. D'Lima et al. ${ }^{(1)}$ relatam que a lesão mecânica é uma forma importante de indução da apoptose em cartilagem. Esta via apoptótica seria induzida pela ativação da cadeia molecular das caspases que conduzem a alterações características do DNA e de outros continentes da célula. Estes autores também mostram ser possível inibir o processo de apoptose dos condrócitos e aumentar a sobrevida celular por meio da utilização de inibidores das caspases ${ }^{(88)}$.

D'Lima et al. ${ }^{(1)}$ destacam o curso de tempo da apoptose, ou seja, o intervalo de tempo utilizado pela célula para ordenar toda a sequência de eventos celulares e de ativação enzimática que conduzem ao evento final, a apoptose. Este curso de tempo tem significado especial, pois seria determinante para uma possível janela terapêutica moduladora do processo apoptótico. 


\subsection{OSTEOARTRITE PÓS-TRAUMÁTICA}

A osteoartrite ou artrose pós-traumática (OAPT), como descrita por McKinley et al. ${ }^{(89)}$, representa o estágio final da falência, em nível orgânico, do trauma da cartilagem, que ocorre após a fratura intra-articular. Lesões traumáticas no joelho podem aumentar o risco de desenvolvimento da artrose em 1,7 a 5 vezes, conforme alguns autores ${ }^{(90,91)}$.

Lawrence et al. ${ }^{(92)}$ descrevem que a despeito da estabilização cirúrgica e mecânica da articulação agudamente lesionada, o risco de OAPT permanece elevado. Sugerem, também, três fases diferentes para a fisiopatologia da OAPT: fase aguda, na qual ocorre derrame articular, hemartrose, secreção de citocinas inflamatórias (sobretudo IL-1 e TNF- $\alpha$ ) e marcadores do catabolismo da cartilagem; fase intermediária, caracterizada pela redução da inflamação articular, mantendo o catabolismo articular, mas ainda sem achados radiológicos típicos de artrose; e a fase tardia, caracterizada pela artrose radiográfica.

Com relação aos condrócitos, Aigner et al. ${ }^{(69)}$ sugerem a divisão do processo da artrose em três estágios: Primeiro, os condrócitos ativam seus mecanismos sintético-anabólicos. Segundo, os condrócitos são submetidos a uma modulação fenotípica, acarretando uma alteração do perfil da expressão genética da células do tecido doente. Terceiro, os condrócitos são submetidos ao processo de morte celular, podendo ser via necrose ou via apoptose. 
Borrelli et al. ${ }^{(13)}$ sugerem que a resposta da cartilagem ao impacto mecânico pode variar conforme o tipo de trauma. Em certas circunstâncias, tanto um trauma mecânico agudo como uma carga anormal crônica podem predominar no processo de degeneração da cartilagem. Isto pode ser o motivo pelo qual algumas lesões articulares progridem rapidamente, como descrito por Teeny et al. ${ }^{(93)}$, e outras degeneram mais lentamente, como relatado por Volpin et al. ${ }^{(94)}$.

$\mathrm{Na}$ busca da melhoraria de resultados clínicos para os traumas agudos da cartilagem articular, emergiu uma grande quantidade de evidência científica, demonstrando que o efeito do trauma mecânico agudo (apoptose e necrose dos condrócitos, disfunção biossintética dos condrócitos) exerce um importante e, possivelmente, um dominante papel na etiologia da artrose pós-traumática ${ }^{(1,95,96)}$. Por isso, como destacam McKinley et al. ${ }^{(89)}$, "é possível que um tratamento mais efetivo para prevenir a OAPT possa mitigar ou parar o efeito lesivo do trauma mecânico agudo".

\subsection{PREVENÇÃO DA APOPTOSE PÓS-TRAUMÁTICA DOS CONDRÓCITOS}

Ao perceberem que a morte dos condrócitos tem um papel importante no desenvolvimento da artrose pós-traumática, diversos autores começaram a investigar a influência de agentes que possam prevenir a apoptose e aumentar a sobrevida dessas células condrais. 
Nestes trabalhos, ocorre uma variação em relação ao modelo contusional, ao animal utilizado, ao agente, ao momento da intervenção e ao método de avaliação da apoptose.

Darryl D’Lima e seu grupo de pesquisadores da Califórnia publicaram, em $2006^{(21)}$, um estudo que utilizou um modelo experimental de artrose em coelhos por meio da secção cirúrgica do ligamento cruzado anterior (LCA). Dois grupos foram criados, cada um com nove coelhos. Após 1 semana, foi injetada, na articulação operada, a substância Z-VAD-FMK (um inibidor não seletivo de caspases). Outras três doses semanais foram repetidas e depois de 9 semanas, os animais foram abatidos e a cartilagem dos joelhos foi avaliada por técnicas de macroscopia, histologia (Safranina-O) e imunohistoquímica. A análise dos resultados forneceu um suporte direto do papel da morte celular na patogênese da artrose. Também mostrou que os inibidores das caspases reduziram a gravidade das lesões na artrose experimental.

Díaz-Gallego et al. ${ }^{(97)}$, em 2005, estudaram, em dois grupos de 16 coelhos cada, a apoptose e os níveis de NO na cartilagem na artrose experimental. No modelo, foi realizada secção cirúrgica do LCA bilateral dos joelhos e somente nos joelhos direitos foi injetado o $\mathrm{AH}$; no primeiro grupo, após 5 semanas do procedimento de indução da artrose e no segundo, após 10 semanas. Para a avaliação da apoptose nos condrócitos, foi usada a técnica TUNEL (Terminal deoxynucleotidyl transferase dUTP nick end labeling) e os níveis de NO foram medidos na cultura de cartilagem. Ao analisar os resultados, concluíram que a administração do $\mathrm{AH}$ foi eficaz na 
redução dos níveis de apoptose e dos níveis de $\mathrm{NO}$ em comparação com os joelhos não tratados. Além disso, os resultados mostraram-se ainda melhores no grupo que recebeu precocemente o tratamento com $\mathrm{AH}$. Desta forma, os autores destacam a importância do intervalo de tempo entre a lesão condral e o tratamento, para se obter menores graus de danos na cartilagem.

Em 2009, Hurtig et al. ${ }^{(98)}$ estudaram o progresso da degeneração da cartilagem em resposta a uma lesão traumática. Em ovelhas, utilizaram um dispositivo para contusão direta da cartilagem por meio de uma pequena artrotomia de ambos os joelhos. Foram criados três grupos diferentes, cada um com nove ovelhas. Em um dos joelhos, foram injetadas duas doses semanais (uma por semana) de BMP-7 (Proteína morfogênica óssea - 7) e placebo no joelho contralateral, sendo que: grupo A - imediatamente; grupo B - 21 dias; e grupo C - 90 dias após a contusão. Cada grupo foi avaliado quanto à macroscopia da lesão, quantidade de liberação de GAG, pela coloração por Safranina-O, e nível de apoptose, pelo método TUNEL, da cartilagem. Concluíram que a BMP-7 comportou-se como um condroprotetor para as lesões condrais pós-traumáticas quando administrada dentro dos primeiros 21 dias. No entanto, este efeito não foi identificado nos joelhos tratados após 90 dias da contusão, nos quais os níveis de apoptose e dos outros marcadores de degradação de cartilagem foram semelhantes aos dos joelhos não tratados.

Mais recentemente, Rezende et al. ${ }^{(28)}$ apresentaram um modelo de estudo do efeito do plasma rico em plaquetas (PRP) na apoptose de 
condrócitos após a lesão traumática. Neste, a contusão da cartilagem dos joelhos de coelhos foi conseguida por meio de um mecanismo de contusão indireta. Em um dos joelhos foi injetado PRP imediatamente após a contusão, e no outro, solução salina. A apoptose foi avaliada por microscopia eletrônica e, após a análise dos resultados, concluíram que o uso do PRP, imediatamente após a contusão, pode reduzir o número de apoptose pós-traumática na cartilagem articular. 
3 MÉTODOS 
O estudo foi aprovado pelo Comitê de Ética em Pesquisa da Universidade de São Paulo sob o protocolo número 884/09 (Anexo 1). Foi realizado no Laboratório de Investigação Médica - 41 (LIM 41), no Instituto de Ortopedia e Traumatologia do Hospital das Clínicas da Faculdade de Medicina da Universidade de São Paulo.

O modelo experimental seguiu os princípios éticos do Colégio Brasileiro de Experimentação Animal (COBEA), da American Veterinary Medical Association (AVMA) e do Institute of Animal Care and Use Committee (IACUC) para a manutenção, anestesia, analgesia e eutanásia dos animais.

\subsection{DESENHO DO ESTUDO}

O desenho de estudo desenvolvido foi do tipo experimental randomizado em 20 vinte coelhos (40 joelhos) adultos jovens da raça Nova Zelândia. Todos com idade média de 8 semanas, peso entre 4 e $6 \mathrm{~kg}$, e provenientes do Centro de Bioterismo da Faculdade de Medicina da USP.

Neste modelo, foram criados dois grupos distintos: grupo joelhoscontrole e grupo joelhos-intervenção, em cada coelho. Ou seja, cada animal recebeu de um lado a intervenção estudada e do lado contralateral teve seu 
controle, permitindo, desta forma, realizar uma análise pareada da intervenção. A distribuição dos lados (direito ou esquerdo) para cada grupo foi feita de acordo com uma lista randomizada em bloco.

Em seguida, foi executada a contusão articular conforme modelo protocolado e descrito adiante. Foram feitas as intervenções propostas e, na sequência, o estudo da histologia condral.

O preparo das lâminas e a leitura histológica foram realizados por profissional qualificado. Este, em nenhum momento, obteve conhecimento do protocolo de intervenção, sendo restringido às informações necessárias para realizar os procedimentos laboratoriais.

\subsection{MODELO CONTUSIONAL}

Utilizou-se o protocolo de anestesia preconizado pelo Canadian Council of American Care e também citado por Reiff ${ }^{(99)}$. Cada animal recebeu aplicação intramuscular de uma solução contendo $40 \mathrm{mg} / \mathrm{kg}$ de quetamina a $10 \%$, associada a $5 \mathrm{mg} / \mathrm{kg}$ de cloridrato de xilazina a $2 \%$, na região proximal do membro pélvico.

$\mathrm{Na}$ posição supina, o modelo contusional descrito por Mazières ${ }^{(23)}$ foi reproduzido três vezes em cada joelho. Uma contusão fechada da patela e do côndilo femoral medial é causada pelo impacto de $1 \mathrm{~kg}$ de peso, com superfície plana circular (4 cm de diâmetro), lançado de 1 metro de altura (Figuras 4 a 6$)$. 


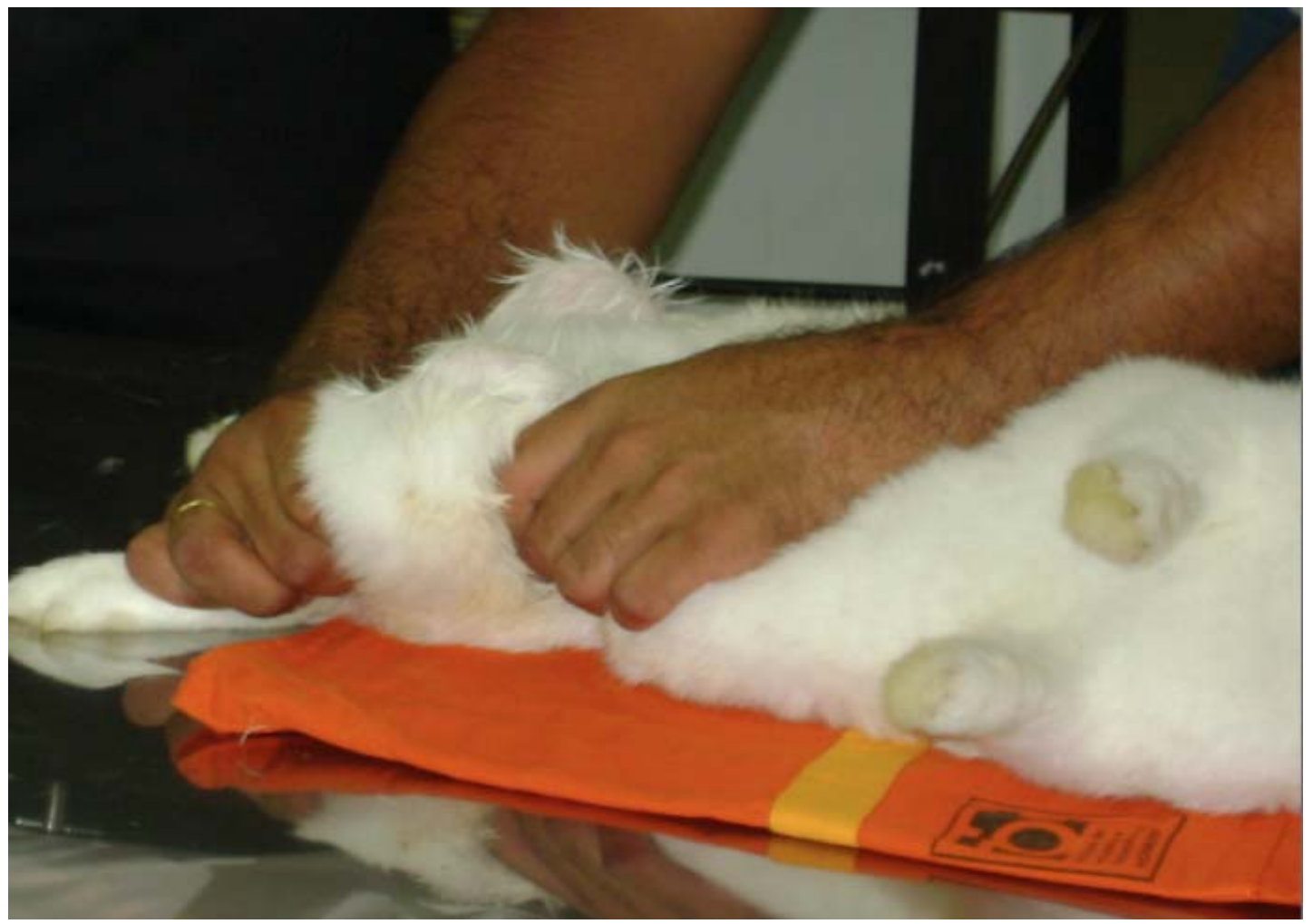

Figura 4 - Preparação do coelho para a contusão no joelho esquerdo

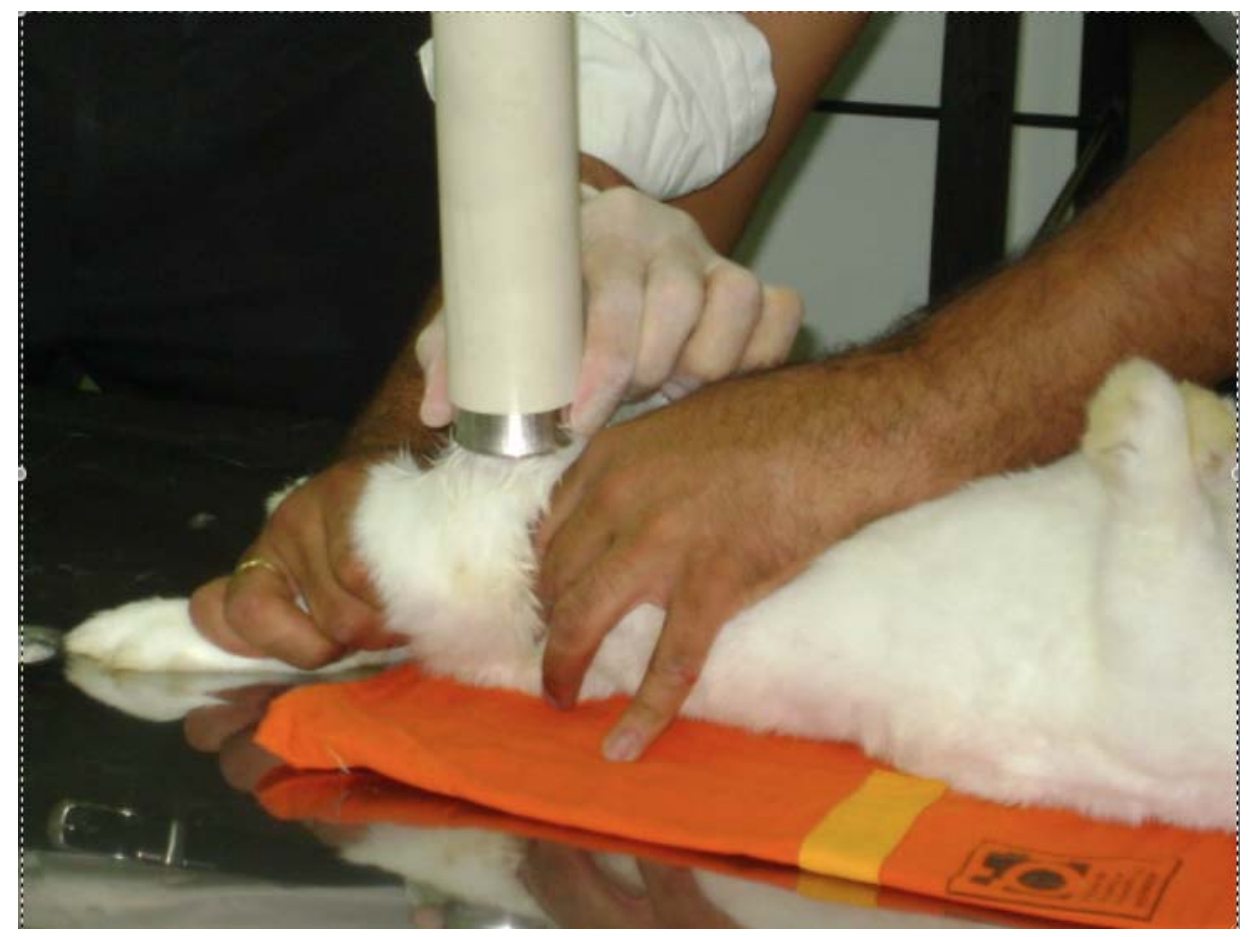

Figura 5 - Contusão no joelho esquerdo 


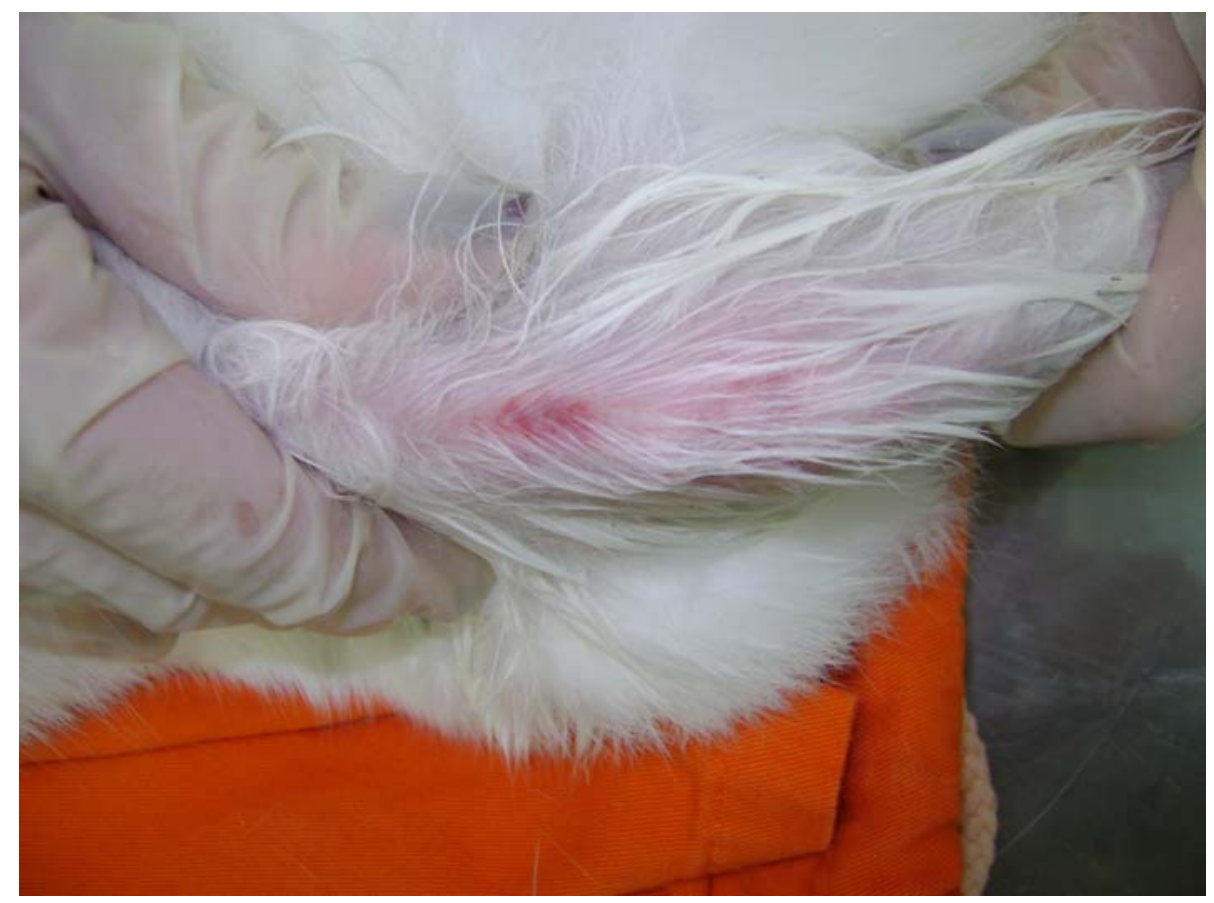

Figura 6 - Hiperemia reacional pós-contusão

No período após a contusão, os animais receberam: enrofloxacina na dose de $10 \mathrm{mg} / \mathrm{kg}$ a cada 12 horas, via subcutânea, por 7 dias; meloxicam na dose de $0,1 \mathrm{mg} / \mathrm{kg}$ a cada 24 horas, via subcutânea, por 4 dias; e Cloridrato de tramadol na dose de $4 \mathrm{mg} / \mathrm{kg}$ a cada 12 horas, via subcutânea, por 3 dias pós-contusão.

Os animais foram mantidos no Centro de Bioterismo do Instituto de Ortopedia e Traumatologia do Hospital das Clínicas da Universidade de São Paulo, com água e ração ad libitum, confinados em gaiolas $(60 \mathrm{~cm} \times 60 \mathrm{~cm}$ x $40 \mathrm{~cm}$ ) sem nenhuma imobilização e monitorados por profissionais bioteristas e veterinários para controle de infecção de outras complicações. 


\subsection{INTERVENÇÃO}

Nos joelhos-controle foram injetados $2 \mathrm{ml}$ de solução salina a 0,9\% de $\mathrm{NaCl}$ e nos joelhos-intervenção, $\mathrm{AH}$ em alta dose, ou seja, $2 \mathrm{ml}(20 \mathrm{mg})$ de injeção intra-articular de AH (Polireumin®, TRB-Pharma® - Suiça).

A frequência de administração das medicações obedeceu à seguinte cronologia: primeira dose, imediatamente após a lesão, e outras doses subsequentes nos $3^{\circ}, 7^{\circ}, 10^{\circ}, 14^{\circ}, 17^{\circ}$ e $21^{\circ}$ dias pós-contusão.

Os procedimentos de injeção intra-articular foram realizados no centro de cirurgia experimental do IOT-FMUSP, após serem submetidos à administração intramuscular da associação de quetamina (35 mg/kg) e midazolam (1 mg/kg) e propofol em dose padrão de $4 \mathrm{ml}$ endovenoso, de modo a diminuir o estresse, dor e facilitar a contenção do animal.

\subsection{HISTOLOGIA}

Após 30 dias da contusão (final do experimento), todos os animais foram sacrificados. A eutanásia foi realizada com a administração de tiopental sódico, na dose $75 \mathrm{mg} / \mathrm{kg}$ por via endovenosa. O descarte dos animais foi realizado pelo centro de material biológico da Universidade de São Paulo. 
Logo após o procedimento de eutanásia, foi realizada a incisão parapatelar medial para acesso ao joelho e, em seguida, deslocamento lateral da patela para a visualização da tróclea femoral. A coleta de material para a histologia foi feita por meio da biópsia da cartilagem da tróclea e do côndilo medial do fêmur, sem colher osso subcondral (Figura 7).

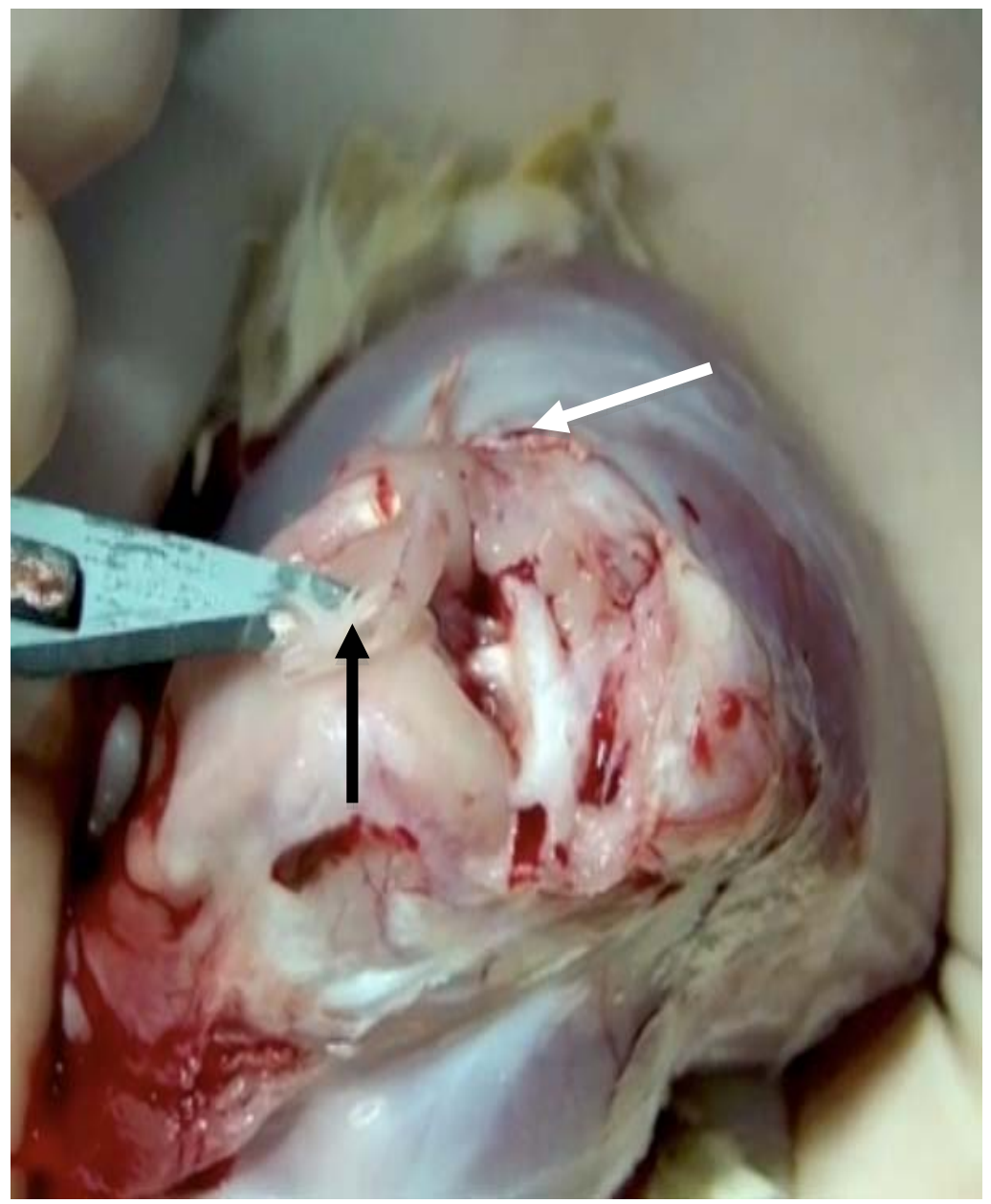

Figura 7 - Fotografia da coleta do material para a histologia. No detalhe: o joelho direito encontra-se em flexão de $90^{\circ}$, com a patela luxada lateralmente. Cartilagem da tróclea femoral, sendo dissecada pela lâmina de bisturi (seta cheia em branco) e côndilo femoral-lateral (seta cheia em preto) 
O tecido fixado em formol foi processado para estudo histopatológico, sendo embebido e incluído em blocos de parafina.

A partir dos blocos de parafina, foram feitas secções com $5 \mu \mathrm{M}$ de espessura, obtidas em micrótomo e depois colocadas em lâminas de vidro previamente silanizadas.

As lâminas com as secções de tecido foram coradas com Hematoxilina e Eosina para avaliar as condições das secções e do tecido e se consideradas adequadas foram submetidas à reação de imunohistoquímica, usando o kit ApopTag® Peroxidase in situ Apoptosis Detection Kit (USA).

O protocolo de preparo histopatológico seguiu as orientações recomendadas pelo fabricante do kit (Anexo 3).

\subsubsection{INTERPRETAÇÃO}

A leitura das lâminas foi feita por meio da microscopia óptica. A reação positiva indicando apoptose foi representada por células com núcleos corados de cor castanha. A reação negativa indicando células viáveis tem o núcleo corado pela hematoxilina de cor azul-escuro (Figura 8). 


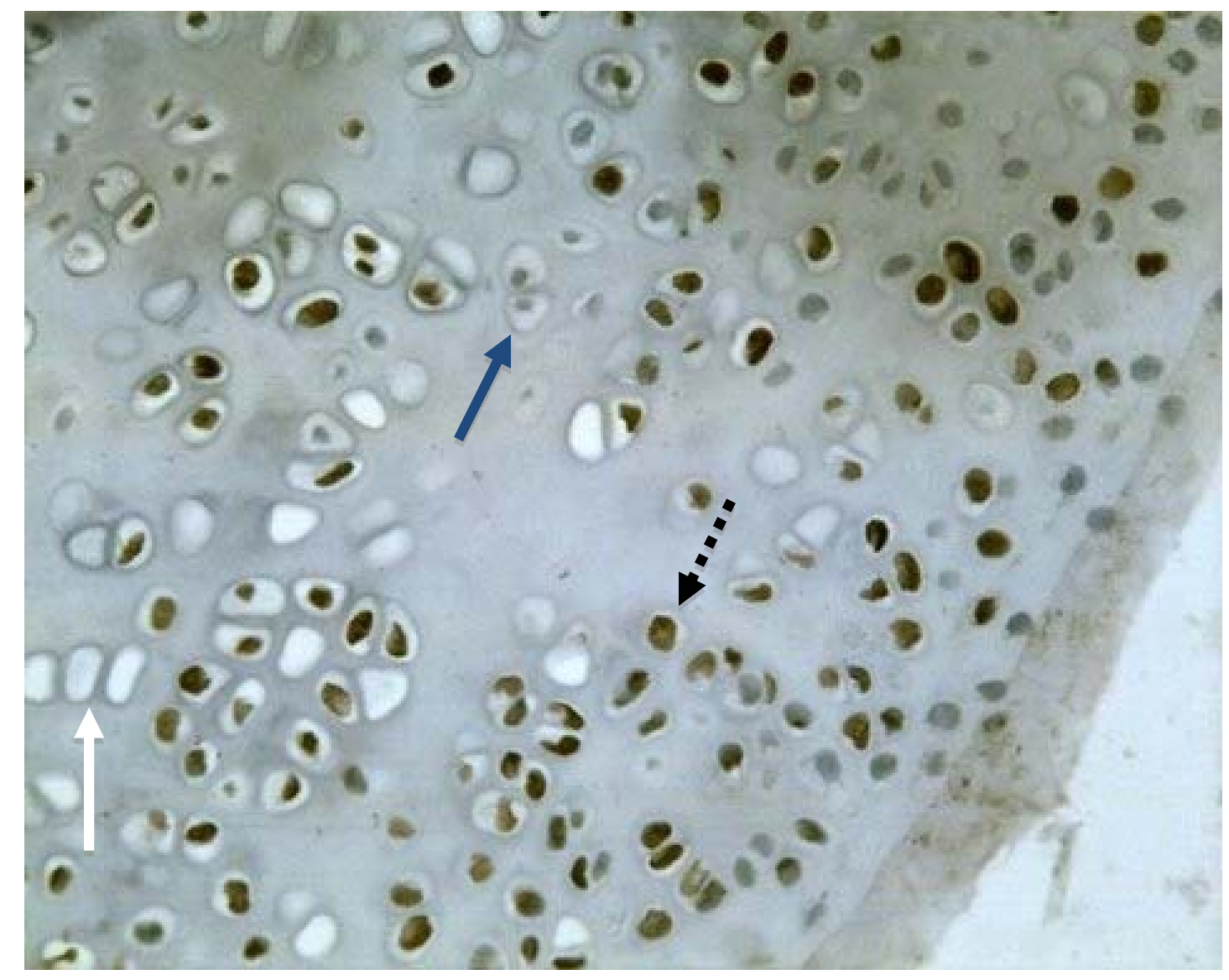

Figura 8 - Micrografia da lâmina preparada pela técnica de TUNEL (aumento de 400x), mostrando núcleos de condrócitos corados em azul-escuro (células viáveis, seta cheia em azul), núcleos corados em castanho (núcleos em apoptose, seta pontilhada) e condroplastos (espaços vazios, setas cheias em branco)

\subsubsection{CONTAGEM DAS CÉLULAS}

A totalidade das células presentes nas secções foi contada, evitando as áreas com artefatos sobretudo com dobra ou esgarçamento de tecido. A contagem foi feita visualmente com contador manual. 
Foi contada a totalidade de células representadas pelas células com núcleos corados de cor castanha e as de núcleo azul. Não foram computados os condroplastos.

\subsection{ANÁLISE ESTATÍSTICA}

A análise estatística foi realizada com o auxílio do programa de cálculos estatísticos SPSS ${ }^{\circledR}$ v.15 e pelo $\mathrm{EXCEL}^{\circledR}$ v. 2003. A hipótese testada $\mathrm{H}_{0}$ foi: a média da diferença entre o percentual de apoptose entre os joelhos tratados (joelhos intervenção) e não tratados (joelhos controles) é igual a zero. As medidas foram comparadas com uso de Teste t-student pareado e foi respeitado o nível de significância (erro alfa) de 5\%. Para avaliar a correlação entre as diferentes variáveis, foi empregado o teste de Pearson.

Assumindo um poder de $80 \%$, um erro alfa de $5 \%$, um índice de desvio-padrão de 15 para cada grupo e a diferença da média de $20 \%$, foi calculado um número de nove sujeitos por grupo necessário para realizar o estudo. Respeitando o limite mínimo de indivíduos, desenhou-se o estudo com 20 sujeitos por grupo, garantindo, desta forma, uma amostra adequada. Para atingir os objetivos descritos, usou-se o Teste de t-student para dados pareados. Este teste é uma alternativa para amostras dependentes (forma pareada), ou seja, as duas variáveis em estudo são observadas no mesmo indivíduo, o que evita viés de seleção ${ }^{(100)}$. Além disso, o lado do joelho 
submetido à intervenção foi escolhido de forma aleatória, visando a reduzir viés de aferição. 
4 RESULTADOS 
Para elaboração da análise dos dados foram observados 20 coelhos, e cada um possuía de um lado o joelho controle e do outro o joelho intervenção, como descrito anteriormente. Dois dos coelhos morreram durante o experimento, sendo analisados os 18 restantes.

Para responder ao objetivo do estudo a análise dos dados absolutos seria inconclusiva pela grande variação do número de células encontradas (Anexo 4). À semelhança da literatura ${ }^{(17)}$, foram descritos os percentuais de apoptose em cada joelho e os pesos iniciais e finais dos coelhos, com uso de medidas-resumo (média, desvio-padrão, mediana, mínimo e máximo) (Tabela 1).

Tabela 1 - Descrição dos pesos dos coelhos e dos percentuais de apoptose e resultado dos testes comparativos

\begin{tabular}{|c|c|c|c|c|c|c|c|}
\hline Variável & Média & $\mathrm{DP}^{1}$ & Mediana & Mínimo & Máximo & $\mathrm{N}^{2}$ & $\mathrm{p}^{*}$ \\
\hline Peso inicial & 4878,61 & 421,45 & 4875 & 4250 & 6100 & 18 & \multirow{2}{*}{0,023} \\
\hline Peso final & 5043,33 & 399,55 & 5000 & 4450 & 6120 & 18 & \\
\hline$\%$ apoptose controle & 68,01 & 19,73 & 67,05 & 18,50 & 95 & 18 & \multirow{2}{*}{$<0,001$} \\
\hline$\%$ apoptose $\mathrm{AH}$ & 53,52 & 18,09 & 54,10 & 5,50 & 80,50 & 18 & \\
\hline
\end{tabular}


Os dados da Tabela 1 mostram o peso médio dos coelhos que aumentou do início para o final do estudo de forma significativa $(p=0,023)$. Também mostram a redução significativa no percentual médio de apoptose nos joelhos que receberam ácido hialurônico $(p<0,001)$ (Gráfico 1).

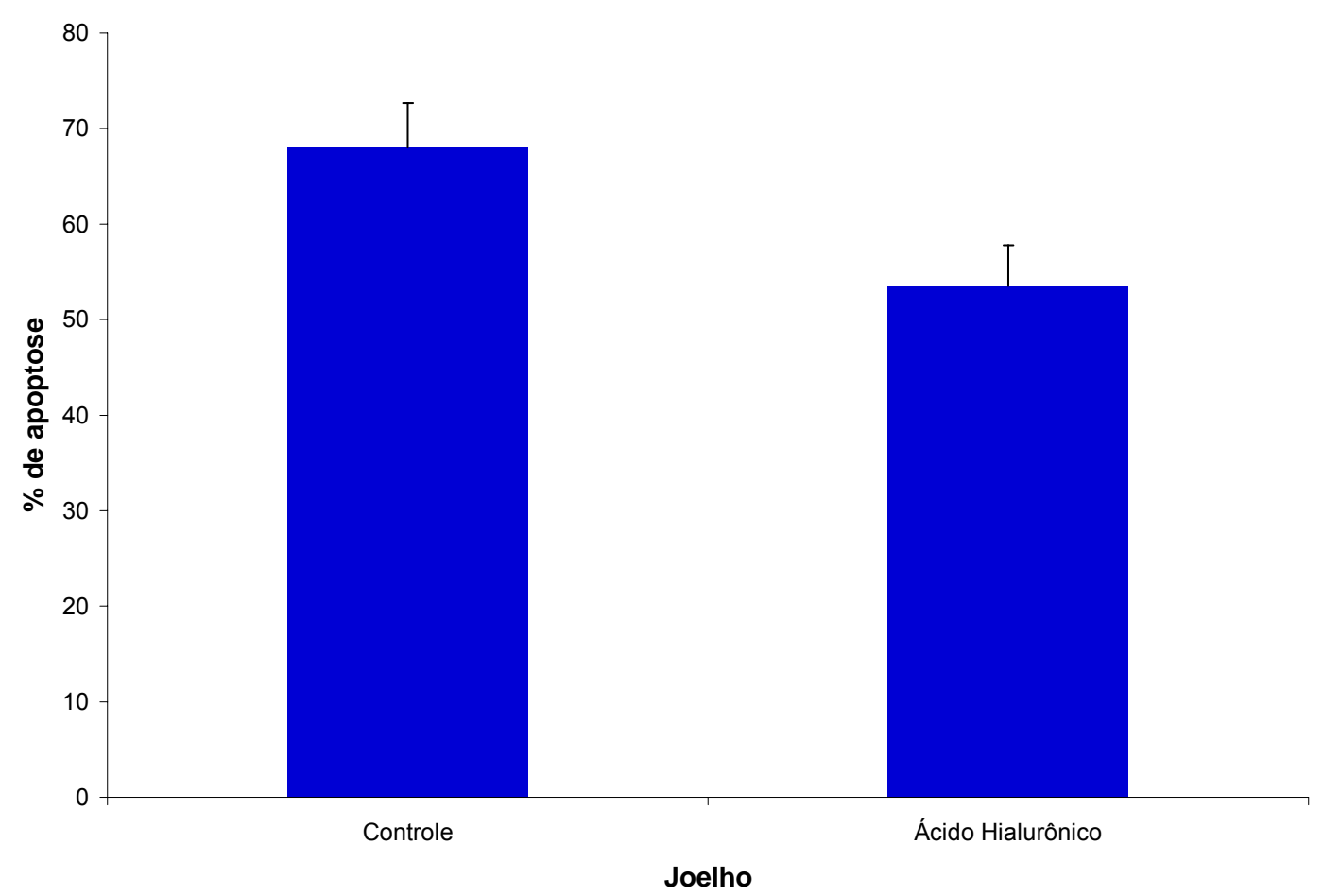

Gráfico 1 - Percentuais médios de apoptose em cada joelho e respectivos erros-padrões 
As correlações de Pearson ${ }^{(100)}$ entre as diferenças percentuais de apoptose entre os grupos joelhos-controle e joelhos-intervenção com as alterações de peso e com o número total de células analisadas para verificar a existência de relação entre as medidas foram calculadas, conforme os dados da Tabela 2.

Tabela 2 - Resultado das correlações de Pearson entre as diferenças no percentual de apoptose e alteração no peso e total de células analisadas

\begin{tabular}{lccc}
\hline Variável & Correlação & $\mathbf{N}^{*}$ & $\mathbf{p}$ \\
\hline Alteração no peso (final - inicial) & 0,091 & 18 & 0,448 \\
Número total de células & $-0,093$ & 18 & 0,713 \\
\hline
\end{tabular}

Fonte: Dados da pesquisa

* número de joelhos

Os dados mostram (Gráficos 2 e 3) que não houve correlação significativa entre as diferenças no percentual de apoptose e a alteração no peso e total de células analisadas $(p>0,05)$. 


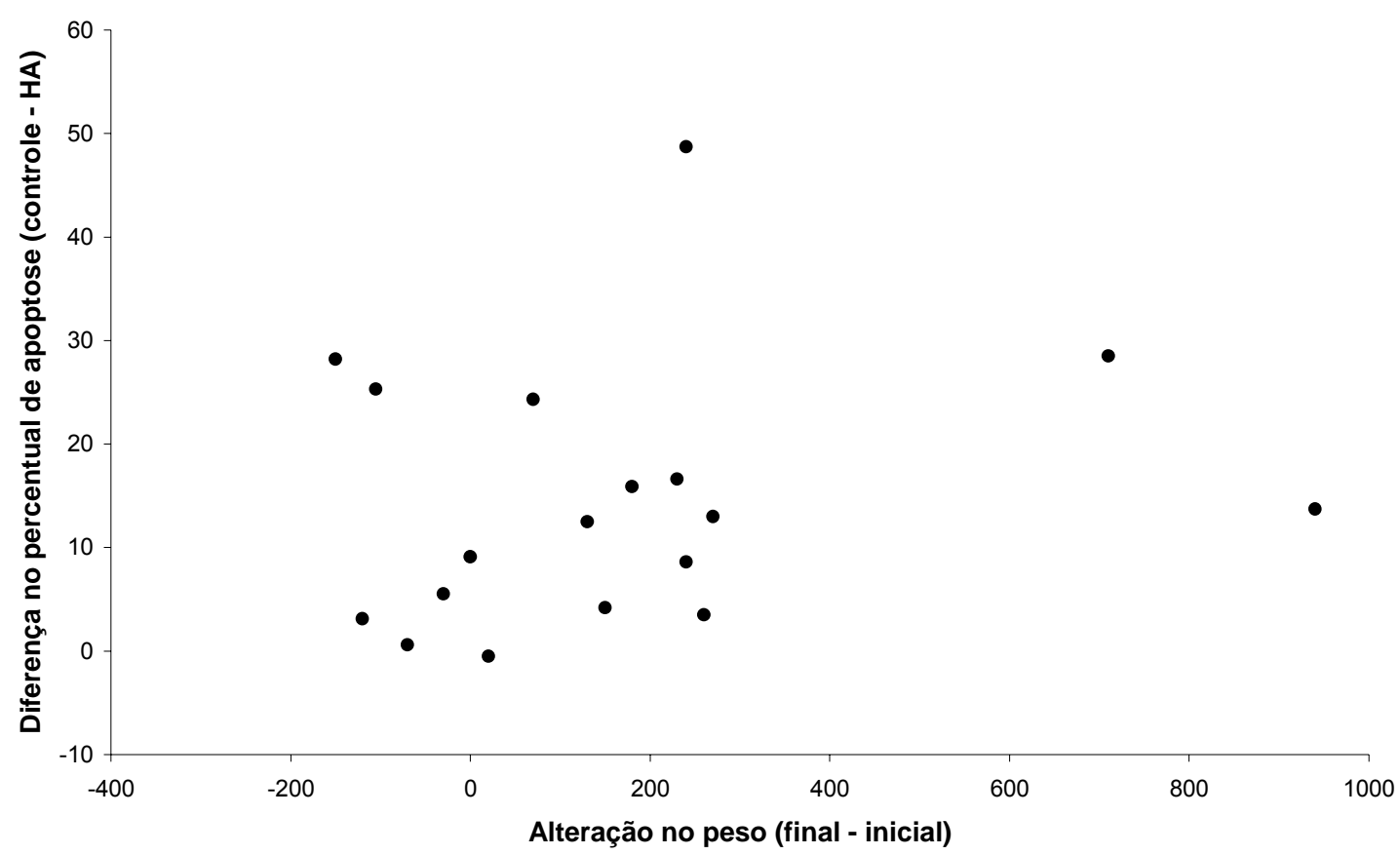

Gráfico 2 - Diagrama de dispersão entre a diferença no percentual de apoptose e a alteração no peso

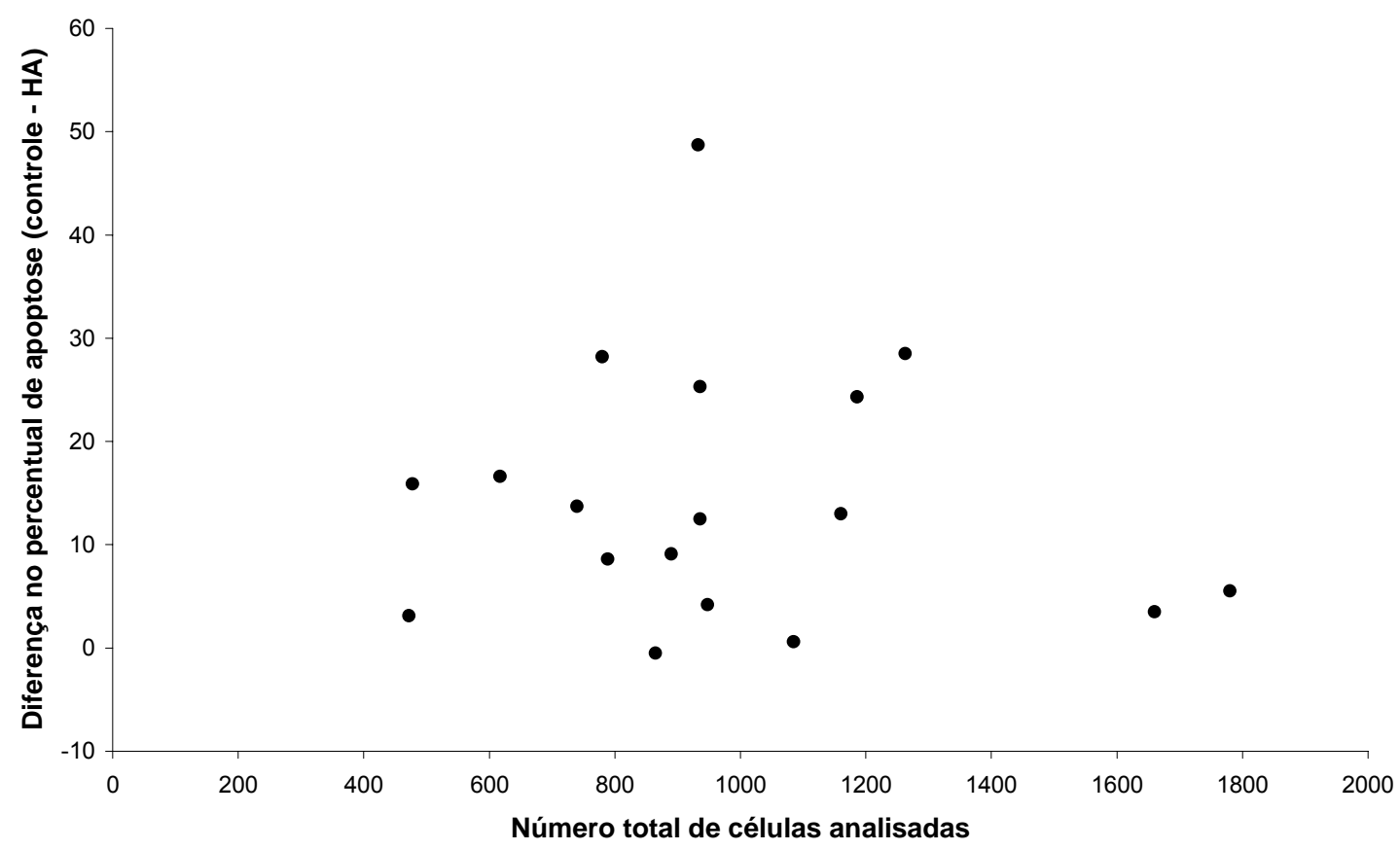

Gráfico 3 - Diagrama de dispersão entre a diferença no percentual de apoptose e o total de células 


\section{DISCUSSÃO}


Os pesquisadores têm obtido um progresso significativo no entendimento da ciência básica presente entre o trauma, a morte dos condrócitos e a artrose pós-traumática. Em 2010, McKinley et al. ${ }^{(89)}$ publicaram um artigo revisando os trabalhos mais recentes que investigam a morte de condrócitos relacionada tanto ao trauma como à disfunção articular. Baseados nessas publicações, pôde-se começar a mudar o nível de compreensão da relação entre as fraturas e lesões condrais com o desenvolvimento da artrose pós-traumática.

Para estes mesmos autores, os condrócitos que sofreram impacto morrem tanto por necrose como por apoptose. Martin et al. ${ }^{(96)}$ descrevem que a lesão mecânica induz à morte aguda dos condrócitos (nas primeiras 12 horas após o impacto) via necrose celular e, secundariamente, após a ativação de uma cascata metabólica específica, os condrócitos passam a morrer por via apoptótica. Da mesma forma, D’Lima et al. ${ }^{(27)}$ concluíram que a apoptose dos condrócitos é o modo predominante de morte nos primeiros dias após a lesão por impacto. Desta forma, entende-se que a apoptose é o processo mantenedor da morte celular em resposta ao impacto inicial. Além disso, é a via de morte passível de inibição medicamentosa, contribuindo para a preservação da celularidade da cartilagem após o trauma.

Ao entender o mecanismo em níveis celular e molecular, pesquisadores visualizaram a oportunidade para desenvolver modelos que 
pudessem testar as intervenções terapêuticas desse processo degenerativo da cartilagem articular. Mazières et al. ${ }^{(23)}$ foram um dos primeiros grupos a publicarem um modelo experimental que mostrasse o efeito redutor da destruição da cartilagem articular induzida pelo impacto por meio da administração da diacereína.

Em 2001, D’Lima et al. ${ }^{(1)}$ publicaram os resultados de um estudo demonstrando que o trauma mecânico induz a apoptose dos condrócitos, ao mesmo tempo em que sugerem uma janela terapêutica capaz de inibir tal processo. Em 2006(21), o mesmo grupo publicou seus resultados que mostraram a significativa redução da gravidade da lesão da cartilagem no modelo de artrose experimental por meio da inibição das caspases, que estão presentes no processo da apoptose dos condrócitos.

Buscando contribuir com essa investigação no campo da ciência básica da artrose pós-traumática, propusemos um estudo com o objetivo de verificar o efeito do uso intra-articular do $\mathrm{AH}$ no processo de apoptose de condrócitos induzida pelo trauma.

Diferentes espécies animais têm sido utilizadas em pesquisas para o estudo de vitalidade dos condrócitos após a lesão traumática: ratos $^{(101)}$,

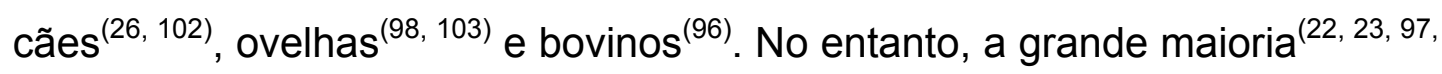
104-107) utiliza coelhos, da mesma forma que o atual estudo. Esta espécie possui custo de aquisição e de manutenção relativamente baixo quando comparada com animais de maior porte e possui articulações maiores ao se comparar com os roedores de pequeno porte. 
Da mesma forma que Reiff ${ }^{(99)}$, em 2010, a articulação do joelho foi escolhida por ser uma articulação que sofre elevada solicitação mecânica e por apresentar características anatômicas que facilitam a reprodutibilidade da contusão e sua abordagem cirúrgica, além de possuir fácil acesso para administração intra-articular das substâncias e suficiente capacidade volumétrica, fornecendo ao método maior precisão e segurança.

Os modelos experimentais descritos na literatura com o objetivo de estudar a apoptose, de um modo geral, utilizam meios mecânicos ou meios químicos para produzir a lesão da cartilagem. Dentre os mecânicos, vimos os que seccionaram cirurgicamente o LCA unilateral ${ }^{(22,106)}$ ou bilateral ${ }^{(21,97)}$. Desta forma, a própria marcha do animal sobre os joelhos instáveis produz microtraumas de repetição na cartilagem. Outros como Hurtig et al. ${ }^{(98)} \mathrm{em}$ 2009, utilizaram um equipamento para contusão direta da cartilagem por meio de uma pequena artrotomia ou, como Mazières et al. ${ }^{(23)}$, em 1996, e Rundell et al. ${ }^{(104)}$, em 2005, preferiram a contusão articular fechada. Higgins et al. ${ }^{(107)}$, em 2010, usaram um modelo de fratura intra-articular do côndilo femoral medial para estudo da reação da cartilagem.

Alguns autores induziram a degradação condral por meios químicos, como fizeram Williams et al. ${ }^{(105)}$, em 2003, ao injetarem fragmentos de fibronectina no joelho de coelhos e observaram o nível de liberação de proteoglicanos pela cartilagem.

Dentre os modelos apresentados, foi escolhido o publicado por Mazières et al. ${ }^{(23)}$ em 1996, que reúne características muito próximas da realidade que se pretendia testar. A intenção deste trabalho seria estudar 
apoptose induzida por um trauma pontual de maior energia, sem realizar a artrotomia cirúrgica, semelhante à que ocorre nas fraturas intra-articulares fechadas. Outra característica necessária ao modelo seria a capacidade de indução imediata da apoptose, como mostrada por Mazières et al. ${ }^{(23)} \mathrm{e}$ Rundell et al. ${ }^{(104)}$, diferente de outros modelos que necessitam de um prazo para desencadear o processo de morte programada. Esta característica do modelo experimental é fundamental, pois a intervenção medicamentosa precisaria ser realizada imediatamente após a contusão, na tentativa de interromper a morte celular o mais precocemente possível.

$\mathrm{Na}$ literatura, um aspecto que é variável é o tamanho da amostra necessária para atingir poder estatístico suficiente. D'Lima et al. ${ }^{(21)}$, em 2006, utilizaram nove coelhos/grupo de estudo. Já Rundell et al. ${ }^{(104)}$, em 2005 e Higgins et al. ${ }^{(107)}$, em 2010, seis coelhos/grupo. No presente estudo, foi realizada análise do poder baseada em relatos prévios in vitro $(27,28,98)$.

Muitas substâncias vêm sendo utilizadas para bloquear o processo de apoptose dos condrócitos induzido pelo impacto mecânico, como já relatado: inibidores das caspases ${ }^{(21)}$, glicosamina ${ }^{(22)}$, diacereína ${ }^{(23)}, \mathrm{OP}-1^{(24)}$ e PRP $^{(28)}$. A opção pelo uso do ácido hialurônico foi baseada na facilidade de acesso ao medicamento e na tentativa de aproximar o estudo experimental à prática clínica, que é o objetivo final deste estudo. Como a substância foi injetada dentro articulação, o grupo controle também foi injetado, porém com solução salina a $0,9 \%$ à semelhança de outros trabalhos da literatura ${ }^{(108-110)}$.

Diversos tipos de $\mathrm{AH}$ foram utilizados por outros autores: $\mathrm{AH}$ com pesos moleculares diferentes, entre 0,12-0,6 × $10^{6} \mathrm{Da}^{(26)}, 0,8 \times 10^{6} \mathrm{Da}^{(106)} \mathrm{e}$ 
$1,2 \times 10^{6} \mathrm{Da}^{(97)}$. Em 1999, Wobig et al. ${ }^{(111)}$ consideraram os $\mathrm{AH}$ de baixo peso molecular, as apresentações entre $0,5-0,75 \times 10^{6} \mathrm{Da}$ e os de alto peso molecular, aquelas maiores que $1 \times 10^{6} \mathrm{Da}$. Em 2005, Pietro et al. ${ }^{(37)}$ expuseram a discussão na literatura sobre qual tipo de $\mathrm{AH}$ é mais benéfico para a articulação e, após realizarem um extenso trabalho comparando-se o comportamento reológico de nove tipos diferentes de $\mathrm{AH}$, mostraram a complexidade das interações desses polímeros, não sendo possível determinar qual dos $\mathrm{AH}$ apresentou melhor comportamento. Ainda expuseram um contraste na literatura ao citar Ghosh et $a l^{(112)}$ de um lado e Moreland $^{(39)}$ do outro: aqueles relataram que as preparações de $\mathrm{AH}$ de baixo peso possuem a capacidade aumentada de penetração na MEC da sinóvia, reduzindo a sinovite e restaurando as propriedades reológicas do líquido sinovial. Já Moreland mostrou que os agentes de maior peso molecular estimulam mais a síntese de $\mathrm{AH}$ que os de menor peso, além de fornecerem maior poder analgésico e menor produção de NO.

Diante deste impasse na literatura, optou-se por utilizar o tipo de $\mathrm{AH}$ de baixo peso molecular, pela sua maior capacidade de penetração na MEC e por ser o tipo mais citado nos estudos que envolvem o bloqueio da apoptose de condrócitos em animais. Escolheu-se o Polireumin® (TRBPharma@ - Suíça) que possui peso molecular de 0,5-0,75 x 106 Da.

Com relação à posologia utilizada, decidiu-se por uma dosagem exagerada de $\mathrm{AH}$, tomando como parâmetro a literatura. Na maioria dos

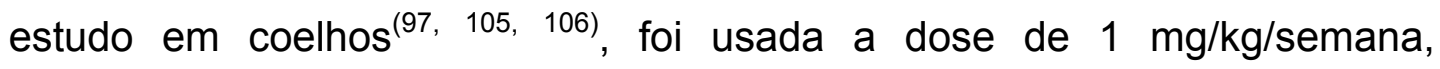
perfazendo, no máximo, cinco doses totais. No presente estudo, 
administrou-se a dose aproximada de $7 \mathrm{mg} / \mathrm{kg} / \mathrm{dose}$, em um total de sete doses. Os motivos para utilização dessa alta dosagem foram os seguintes: 1- garantir uma concentração intra-articular de $\mathrm{AH}$ constante, uma vez que radicais livres presentes em articulações com inflamação produzem um dano oxidativo ao $\mathrm{AH}$, efeito este capaz de diminuir a concentração do $\mathrm{AH}$ no líquido sinovial ${ }^{(113)}$; 2- à medida que o $\mathrm{AH}$ é absorvido, faz uma varredura do radicais livres ${ }^{(114)}$, permanecendo, conforme Akmal et al. ${ }^{(51)}$, no máximo 4 dias, antes de ser eliminado da articulação.

Outro fato que motivou prolongar o tratamento para um total de sete doses (dentro de um período de 21 dias), foi a hipótese de que, ao manter a intervenção durante a maior parte da fase aguda pós-traumática, proposta por Lawrence et al. ${ }^{(92)}$ e que conforme Lohmander et al. ${ }^{(115,116)}$ dura entre $3 \mathrm{e}$ 4 semanas - obter-se-iam melhores resultados. Este motivo também foi embasado no estudo-piloto (não publicado) desenvolvido por nosso grupo, no qual ao testar a mesma metodologia, utilizando quatro doses (dentro de um período de 10 dias) ao invés de sete doses, não foram encontradas diferenças significativas.

O fator tempo é um aspecto importante a ser destacado quando se estuda a apoptose dos condrócitos. De acordo com D'Lima et al. ${ }^{(1)}$, há um intervalo de 6 horas entre o estímulo mecânico e o aumento significativo no percentual da apoptose na cartilagem. Na tentativa de obter-se maior eficácia do tratamento e aproveitar esta janela terapêutica, optou-se, como estratégia, aplicar o $\mathrm{AH}$ imediatamente após o trauma nos joelhos. Este é um diferencial do presente trabalho em relação ao de Diaz-Gallego et al. ${ }^{(97)}$, 
Williams et al. ${ }^{(105)}$ e Echigo et al. ${ }^{(26)}$ que esperaram, respectivamente, 7 dias, 3 dias e 24 horas, para administrarem o $\mathrm{AH}$.

Há variados métodos descritos que são utilizados para avaliar o nível de agressão na cartilagem. Dang e $\mathrm{Kim}^{(117)}$ e Schmitz et al. $^{(118)}$ fizeram uma ampla revisão dos métodos mais importantes e mais presentes nos artigos sobre o tema. Dentre eles, podem ser listados: a avaliação macroscópica pela coloração com a tinta Indiana, usada para corar a cartilagem superficial que auxilia a quantificação da profundidade de perda da cartilagem; coloração com Hematoxilina-Eosina, uma coloração histológica básica para avaliação geral da morfologia e distribuição da célula e do tecido; coloração com Safranina-O e com azul de Toluidina, métodos histoquímicos que coram as glicosaminoglicanas e indicam o quanto foram depletadas da cartilagem; coloração com vermelho Picrosirius e tricômico de Goldner, usadas para visualizar as fibras colágenas e avaliar o calibre e densidade em secções histológicas.

Dang e $\mathrm{Kim}^{(117)}$ descreveram outros métodos mais específicos para identificação do processo de morte celular programada. Conforme estes autores, a apoptose foi classicamente identificada, tendo como base alterações morfológicas visualizadas pela microscopia eletrônica. No entanto, os resultados com esta metodologia foram inconsistentes. Destacaram quatro métodos comuns nos estudos de apoptose de condrócitos induzidos pelo trauma, fazendo uma comparação entre eles. Concluíram que tanto a coloração por TUNEL e análise da desnaturação do DNA usando anticorpos anti-fita simples do DNA (ssDNA), quanto à 
detecção da atividade da Caspase-3 usando anticorpos específicos e ligação in situ de oligonucleotídeo (ISOL) são capazes de distinguir entre condrócitos apoptóticos e não apoptóticos nos modelos experimentais com os mesmos níveis de vantagens entre eles. Blanco et al. ${ }^{(14)}$ reportam que, embora a coloração de TUNEL seja um dos métodos mais específicos da identificação da apoptose, é preciso estar atento para a presença da necrose quando houver casos de extensa degradação do DNA. No entanto, a integridade da membrana plasmática caracteriza a morte celular por apoptose.

No presente estudo, optou-se pelo método de TUNEL pela maior facilidade de acesso aos protocolos laboratoriais e por ser umas das técnicas que, conforme Schmitz et al. ${ }^{(118)}$, é capaz de identificar alterações celulares nas fases precoces da artrose antes das alterações físicas, o que a torna atrativa aos estudos medicamentosos em modelos animais.

Nossos resultados sustentam a hipótese de que o Ácido Hialurônico pode ajudar a preservar os condrócitos após o trauma da cartilagem articular. Isto porque se verificou que o tratamento dos joelhos com $\mathrm{AH}$ inibiu significativamente a morte celular por apoptose da cartilagem.

Observou-se uma redução de $14,49 \%$ no percentual de células apoptóticas por efeito do $\mathrm{AH}$ em nosso modelo experimental. Este resultado é comparável com os encontrados por Rundell et al. ${ }^{(104)}$ que mostraram queda nos índices de morte celular de 31\% (controle) para 16\% nos joelhos tratados com o surfactante polixâmero 188 (P188). Foram verificadas reduções semelhantes descritas por Echigo et al. ${ }^{(26)}$ que administraram $A H$ 
nos joelhos de cães após a secção do LCA e, ao término do estudo, descreveram a taxa de apoptose de $24,5 \%$ (controle) e de $12,7 \%$ (grupo tratado).

Além destas semelhanças descritas, este estudo ratifica a mesma tese apresentada por outros autores $(21,96,98,107)$ : ao indicar agente medicamentoso para obter efeitos benéficos da preservação da viabilidade celular. Apesar da obtenção da redução nas taxas de apoptose com o uso do $\mathrm{AH}$, sabe-se que a taxa residual de $53,52 \%$ seria suficiente para gerar a artrose pós-traumática ${ }^{(17)}$.

Embora Martin et al. ${ }^{(96)}$ também tenham encontrado elevada proporção de células mortas (36\% no grupo tratado com $N$-acetilcisteína), nosso índice foi mais alto que a maioria dos descritos. Inclusive quando se comparam os grupos que não utilizaram agentes antiapoptóticos, como Hashimoto et al. ${ }^{(12)}$ que encontraram $28,7 \%$ de apoptose, e Rundell et al. ${ }^{(104)}$ que verificaram $31 \%$ (no grupo controle) em coelhos; Echigo et al. ${ }^{(26)}$, $24,5 \%$ (no grupo controle) em cães; e D'Lima et al. ${ }^{(3)}, 43 \%$ em bovinos. Estas diferenças podem ser atribuídas às distintas energias de trauma utilizadas nos modelos contusionais.

De acordo com D'Lima et al. $^{(3)}$, existe uma relação direta de doseresposta entre a carga aplicada sobre a cartilagem e as taxas de apoptose dos condrócitos. No presente estudo, a energia cinética acumulada no momento que o peso atinge a patela foi cerca de 9,8 joules $(\mathrm{J})$ em cada impacto, e repetimos o impacto três vezes em cada joelho que totalizou, aproximadamente, $30 \mathrm{~J}$. Ou seja, a energia de um único trauma deste 
estudo foi $63 \%$ mais alta que a apresentada por Rundell et al. ${ }^{(104)}$ que foi de 6 J. O modelo, descrito por Rundell, foi o que se encontrou com maior semelhança ao utilizado por nós, o peso foi de $1,3 \mathrm{~kg}$ e a altura de $46 \mathrm{~cm}$. Com esta energia de trauma, conseguiram mostrar importantes alterações morfológicas na cartilagem e apoptose dos condrócitos de $31 \%$. Por isso, acredita-se que as altas taxas de apoptose encontradas no nosso modelo experimental foram influenciadas pela enorme energia do trauma aplicada no experimento.

A energia do trauma produzida pelo modelo contusional utilizado neste estudo foi superior aos níveis de impactos encontrados em acidentes automobilísticos (cerca de $10 \mathrm{~J})^{(96)}$. As taxas de apoptose após o uso das medicações permaneceram elevadas quando comparadas a outros estudos, como os de Echigo et al. ${ }^{(26)}$ e de Diaz-Gallego et al. ${ }^{(97)}$.

Em resumo, conseguiu-se demonstrar a redução nas taxas de apoptose com o uso do $\mathrm{AH}$. No entanto, os níveis de apoptose permaneceram elevados. Talvez, em traumas de menor energia, o $\mathrm{AH}$ possa ser capaz de reduzir estas taxas a níveis inferiores aos encontrados em modelos de osteoartrite. 
6 CONCLUSÃO 
A utilização de ácido hialurônico injetado no meio intra-articular, iniciado imediatamente após o trauma, reduz as taxas de apoptose de condrócitos de coelhos. 
ANEXOS

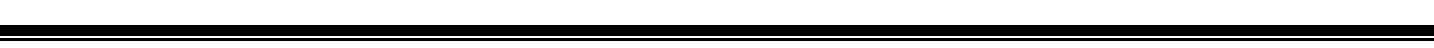




\title{
Anexo 1
}

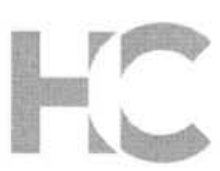

\section{APROVAÇÃO}

A Comissão de Ética para Análise de Projetos de Pesquisa CAPPesa da Diretoria Clínica do Hospital das Clínicas e da Faculdade de Medicina da Universidade de São Paulo, em sessão de 21/10/2009, APROVOU o Protocolo de Pesquisa n 0884/09, intitulado: "EFEITO DO ÁCIDO HIALURÔNICO NA APOPTOSE PÓS-TRAUMÁTICA DE CONDRÓCITOS" apresentado pelo Departamento de ORTOPEDIA E TRAUMATOLOGIA.

Cabe ao pesquisador elaborar e apresentar à CAPPesq, os relatórios parciais e final sobre a pesquisa (Resolução do Conselho Nacional de Saúde n*196, de 10/10/1996, inciso IX.2, letra "c").

Pesquisador (a) Responsável: Márcia Uchôa de Rezende

Pesquisador (a) Executante: Ronald Bispo Barreto da Silva

CAPPesq, 22 de Outubro de 2009

\author{
s.s. \\ Prof. Dr. Eduardo Massad \\ Presidente da Comissão de \\ Ética para Análise de Projetos \\ de Pesquisa
}




\section{Anexo 2}

\section{CIÊNCIA}

O Presidente da Comissāo de Ética para Análise de Projetos de Pesquisa - CAPPesa da Diretoria Clínica do Hospital das Clínicas e da Faculdade de Medicina da Universidade de Sāo Faulo. em 20/04/2011, TOMOU CIÊNCIA das alteraçōes abaixo mencionadas no Protocolo de Pesquisa $n^{\circ}$ 0884/09, intitulado: 'EFEITO DO ÁCIDO HIALURÓNICO NA APOPIOSE PÓS-IRAUMÁTICA DE CONDRÓCITOS." apresentado pelo Departamento de ORTOPEDIA E TRAUMATOLOGIA.

Memo/CC-DOT/53/2011 - datado de 30/03/11:

- Substituição da pesquisadora responsável Márcia Uchoa de Rezende pelo Prof. Arnaldo José Hernandez.

- Comunicado que o protocolo passou a ser dissertação de mestrado de Ronald Bispo Barreto.

- Prorrogação do cronograma por mais 1 ano

- Relatório parcial da pesquisa.

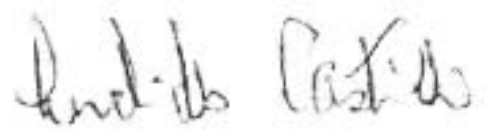

PROF. DR. EUCLIDES AYRES DE CASTILHO Coordenador

Comissāo de Ética para Análise de Projetos de Pesquisa - CAPPesq

Cor ssảo de Fliza wara Análise de Projetos de Pesquisa do HCFMuSP da Diretoia Clinica do Hosprtal das Clinicas da Faculdade de IAtedicina da Universidade de Sao Paub Rua Ovido Pres de Campos $2255^{\circ}$ ansiar - CEP 05403 010 - \$SO Paulo - SP Fore 01130093442 Fax 01130696482 e-mall. 


\section{Anexo 3}

\section{Protocolo da reação para histologia:}

a. Desparafinizar em três banhos de xilol, 5 minutos cada.

b. Passar em dois banhos de álcool (etanol) absoluto, 5 minutos cada

c. Passar em um banho de álcool a $95 \%$ diluído em água deionizada por 3 minutos.

d. Passar em um banho de álcool a 70\%, 3 minutos.

e. Colocar em PBS (Salina tamponada com Fosfato 0,15M) preparada com água deionizada, 5 minutos.

f. Cobrir as secções com solução de Proteinase $K$ na concentração de $20 \mu \mathrm{G}$ por $\mathrm{mL}$, diluída em PBS.

g. Incubar em câmara úmida, temperatura ambiente, 30 minutos.

h. Lavar em água destilada, quatro banhos de 2 minutos cada, usando cubetas de vidro.

i. Bloqueiar a Peroxidase endógena incubando em Peróxido de Hidrogênio a $2 \%$ diluído em PBS durante 5 minutos.

j. Lavar em dois banhos de PBS, 5 minutos cada

k. Aplicar o tampão de equilíbrio (componente do KIT) diretamente sobre as secções e incubar por 1 minuto.

I. Enxugar as bordas das secções para tirar o excesso de líquido.

m. Aplicar a solução da enzima TdT, preparada recentemente, na concentração de $30 \%(30 \mu \mathrm{L}$ de TdT + 70 $\mu \mathrm{L}$ de Tampão de reação).

n. Incubar por 1 hora em câmara úmida a $37^{\circ} \mathrm{C}$.

o. Colocar as lâminas em Tampão bloqueador (componente do KIT) $1 \mathrm{~mL}$ da solução mãe $+34 \mathrm{~mL}$ de água destilada deionizada durante 10 minutos em temperatura ambiente. Usar cubas de vidro.

p. Lavar as lâminas em três banhos de PBS, 1 minuto cada.

q. Enxugar as bordas das secções para tirar o excesso de líquido.

r. Adicionar a solução do anticorpo (antidioxigenina) a $47 \%$ diluída em solução bloqueadora.

s. Incubar por 30 minutos em câmara úmida.

t. Lavar quatro vezes em PBS, 2 minutos cada.

u. Fazer a revelação, usando o KIT de Revelação LSAB plus.

v. Contracorar com Hematoxilina de Harris durante 3 minutos.

w. Desidratar com álcool em concentrações crescentes até álcool absoluto.

x. passar em Xilol, mínimo de 5 minutos.

y. Montar com lamínula usando Bálsamo do Canadá. 
Anexo 4

\begin{tabular}{|c|c|c|c|c|c|}
\hline $\begin{array}{c}\text { Peça } \\
\text { histológica }\end{array}$ & Coelho & Intervenção & $\begin{array}{l}\text { Total } \\
\text { célular }\end{array}$ & $\begin{array}{c}\text { Células } \\
\text { apoptóticas }\end{array}$ & $\begin{array}{c}\text { Taxa de } \\
\text { apoptose } \\
\text { (\%) }\end{array}$ \\
\hline $10-01$ & Coelho 3 & $\mathrm{AH}$ & 269 & 136 & 50,5 \\
\hline $10-02$ & Coelho 3 & Controle & 520 & 329 & 63,0 \\
\hline $10-03$ & Coelho 1 & Controle & 530 & 268 & 50,6 \\
\hline $10-04$ & Coelho 1 & $\mathrm{AH}$ & 360 & 152 & 42,0 \\
\hline $10-05$ & Coelho 8 & Controle & 316 & 198 & 62,7 \\
\hline $10-06$ & Coelho 8 & AH & 620 & 290 & 46,8 \\
\hline $10-07$ & Coelho 4 & Controle & 415 & 77 & 18,5 \\
\hline $10-08$ & Coelho 4 & $\mathrm{AH}$ & 745 & 41 & 5,5 \\
\hline $10-09$ & Coelho 9 & Controle & 691 & 250 & 36,0 \\
\hline $10-10$ & Coelho 9 & $\mathrm{AH}$ & 495 & 163 & 32,9 \\
\hline $10-11$ & Coelho 18 & $\mathrm{AH}$ & 432 & 158 & 36,6 \\
\hline $10-12$ & Coelho 18 & Controle & 433 & 282 & 65,1 \\
\hline $10-13$ & Coelho 20 & Controle & 651 & 560 & 86,0 \\
\hline $10-14$ & Coelho 20 & $\mathrm{AH}$ & 297 & 239 & 80,5 \\
\hline $10-15$ & Coelho 16 & Controle & 340 & 234 & 68,8 \\
\hline $10-16$ & Coelho 16 & $\mathrm{AH}$ & 138 & 60 & 43,5 \\
\hline $10-17$ & Coelho 7 & $\mathrm{AH}$ & 181 & 98 & 54,2 \\
\hline $10-18$ & Coelho 7 & Controle & 291 & 170 & 58,4 \\
\hline $10-19$ & Coelho 17 & Controle & 366 & 268 & 73,2 \\
\hline $10-20$ & Coelho 17 & AH & 251 & 175 & 69,7 \\
\hline $10-21$ & Coelho 5 & $\mathrm{AH}$ & 497 & 343 & 69,0 \\
\hline $10-22$ & Coelho 5 & Controle & 436 & 407 & 93,3 \\
\hline $10-23$ & Coelho 6 & $\mathrm{AH}$ & 328 & 216 & 65,8 \\
\hline $10-24$ & Coelho 6 & Controle & 412 & 269 & 65,3 \\
\hline $10-25$ & Coelho 19 & Controle & 365 & 267 & 73,1 \\
\hline $10-26$ & Coelho 19 & AH & 415 & 301 & 72,5 \\
\hline $10-27$ & Coelho 15 & Controle & 366 & 348 & 95,0 \\
\hline $10-28$ & Coelho 15 & $\mathrm{AH}$ & 570 & 381 & 66,8 \\
\hline $10-29$ & Coelho 13 & AH & 790 & 495 & 62,6 \\
\hline $10-30$ & Coelho 13 & Controle & 870 & 664 & 76,3 \\
\hline $10-31$ & Coelho 2 & Controle & 608 & 384 & 63,1 \\
\hline $10-32$ & Coelho 2 & AH & 655 & 354 & 54,0 \\
\hline $10-33$ & Coelho 11 & $\mathrm{AH}$ & 470 & 207 & 44,0 \\
\hline $10-34$ & Coelho 11 & Controle & 615 & 570 & 92,7 \\
\hline $10-35$ & Coelho 10 & $\mathrm{AH}$ & 830 & 552 & 66,5 \\
\hline $10-36$ & Coelho 10 & Controle & 950 & 790 & 83,1 \\
\hline
\end{tabular}




\section{REFERÊNCIAS}


1. D'Lima DD, Hashimoto S, Chen PC, Colwell CW, Jr., Lotz MK. Human chondrocyte apoptosis in response to mechanical injury. Osteoarthritis Cartilage. 2001 Nov;9(8):712-9.

2. Buckwalter JA. Articular cartilage: injuries and potential for healing. $J$ Orthop Sports Phys Ther. 1998 Oct;28(4):192-202.

3. D'Lima DD, Hashimoto S, Chen PC, Lotz MK, Colwell CW, Jr. In vitro and in vivo models of cartilage injury. J Bone Joint Surg Am. 2001;83A Suppl 2(Pt 1):22-4.

4. Repo RU, Finlay JB. Survival of articular cartilage after controlled impact. J Bone Joint Surg Am. 1977 Dec;59(8):1068-76.

5. Tew SR, Kwan AP, Hann A, Thomson BM, Archer CW. The reactions of articular cartilage to experimental wounding: role of apoptosis. Arthritis Rheum. 2000 Jan;43(1):215-25.

6. Lim JT, Piazza GA, Han EK, Delohery TM, Li H, Finn TS, et al. Sulindac derivatives inhibit growth and induce apoptosis in human prostate cancer cell lines. Biochem Pharmacol. 1999 Oct 1;58(7):1097-107.

7. Rudel T. Caspase inhibitors in prevention of apoptosis. Herz. 1999 May;24(3):236-41.

8. Weinrauch $\mathrm{Y}$, Zychlinsky A. The induction of apoptosis by bacterial pathogens. Annu Rev Microbiol. 1999;53:155-87. 
9. Wong BC, Zhu GH, Lam SK. Aspirin induced apoptosis in gastric cancer cells. Biomed Pharmacother. 1999 Aug;53(7):315-8.

10. Cheng W, Li B, Kajstura J, Li P, Wolin MS, Sonnenblick EH, et al. Stretch-induced programmed myocyte cell death. J Clin Invest. 1995 Nov;96(5):2247-59.

11. DeMeester SL, Cobb JP, Hotchkiss RS, Osborne DF, Karl IE, Tinsley $\mathrm{KW}$, et al. Stress-induced fractal rearrangement of the endothelial cell cytoskeleton causes apoptosis. Surgery. 1998 Aug;124(2):362-71.

12. Hashimoto S, Takahashi K, Amiel D, Coutts RD, Lotz M. Chondrocyte apoptosis and nitric oxide production during experimentally induced osteoarthritis. Arthritis Rheum. 1998 Jul;41(7):1266-74.

13. Borrelli J, Jr., Tinsley K, Ricci WM, Burns M, Karl IE, Hotchkiss R. Induction of chondrocyte apoptosis following impact load. J Orthop Trauma. 2003 Oct;17(9):635-41.

14. Blanco FJ, Guitian R, Vazquez-Martul E, de Toro FJ, Galdo F. Osteoarthritis chondrocytes die by apoptosis. A possible pathway for osteoarthritis pathology. Arthritis Rheum. 1998 Feb;41(2):284-9.

15. Chen CT, Burton-Wurster N, Borden C, Hueffer K, Bloom SE, Lust G. Chondrocyte necrosis and apoptosis in impact damaged articular cartilage. J Orthop Res. 2001 Jul;19(4):703-11.

16. Kim HA, Lee YJ, Seong SC, Choe KW, Song YW. Apoptotic chondrocyte death in human osteoarthritis. J Rheumatol. 2000 Feb;27(2):455-62. 
17. Murray MM, Zurakowski D, Vrahas MS. The death of articular chondrocytes after intra-articular fracture in humans. J Trauma. 2004 Jan;56(1):128-31.

18. Salter RB. The biologic concept of continuous passive motion of synovial joints. The first 18 years of basic research and its clinical application. Clin Orthop Relat Res. 1989 May(242):12-25.

19. Salter RB, Simmonds DF, Malcolm BW, Rumble EJ, MacMichael D, Clements ND. The biological effect of continuous passive motion on the healing of full-thickness defects in articular cartilage. An experimental investigation in the rabbit. J Bone Joint Surg Am. 1980 Dec;62(8):1232-51.

20. Colwell CW, Jr., D'Lima DD, Hoenecke HR, Fronek J, Pulido P, Morris $\mathrm{BA}$, et al. In vivo changes after mechanical injury. Clin Orthop Relat Res. 2001 Oct(391 Suppl):S116-23.

21. D'Lima D, Hermida J, Hashimoto S, Colwell C, Lotz M. Caspase inhibitors reduce severity of cartilage lesions in experimental osteoarthritis. Arthritis Rheum. 2006 Jun;54(6):1814-21.

22. Shikhman AR, Amiel D, D'Lima D, Hwang SB, Hu C, Xu A, et al. Chondroprotective activity of $\mathrm{N}$-acetylglucosamine in rabbits with experimental osteoarthritis. Ann Rheum Dis. 2005 Jan;64(1):89-94.

23. Mazieres B, Blanckaert A, Thiechart M, Viguier G. [Diacetylrhein administrated "curatively" in an experimental model of post-contusion osteoarthritis in rabbits]. Rev Prat. 1996 Dec 1;46(19 Spec No):S42-5.

24. Chubinskaya S, Hurtig M, Rueger DC. OP-1/BMP-7 in cartilage repair. Int Orthop. 2007 Dec;31(6):773-81. 
25. Scotto d'Abusco A, Corsi A, Grillo MG, Cicione C, Calamia V, Panzini $\mathrm{G}$, et al. Effects of intra-articular administration of glucosamine and a peptidyl-glucosamine derivative in a rabbit model of experimental osteoarthritis: a pilot study. Rheumatol Int. 2008 Mar;28(5):437-43.

26. Echigo R, Mochizuki M, Nishimura R, Sasaki N. Suppressive effect of hyaluronan on chondrocyte apoptosis in experimentally induced acute osteoarthritis in dogs. J Vet Med Sci. 2006 Aug;68(8):899-902.

27. D'Lima DD, Hashimoto S, Chen PC, Lotz MK, Colwell CW, Jr. Cartilage injury induces chondrocyte apoptosis. J Bone Joint Surg Am. 2001;83-A Suppl 2(Pt 1):19-21.

28. Rezende MU, Barreto RB, Bassit ACF, Tatsui NH, Sadigursky D, Bolliger Neto R. Effect of platelet-rich plasma on impact-induced chondrocyte apoptosis. Acta Ortopédica Brasileira. 2011;19(2):102-5.

29. Necas J, Bartosikova L, Brauner P, Kolar J. Hyaluronic acid (hyaluronan): a review. Vet Medicina. 2008;53(8):397-411.

30. Laurent TC, Fraser JR. Hyaluronan. FASEB J. 1992 Apr;6(7):2397404.

31. Meyer K. Chemical structure of hyaluronic acid. Fed Proc. 1958 Dec;17(4):1075-7.

32. Balazs EA, Laurent TC, Jeanloz RW. Nomenclature of hyaluronic acid. Biochem J. 1986 May 1;235(3):903.

33. Laurent T. The biology of hyaluronan. Introduction. Ciba Found Symp. 1989;143:1-20. 
34. Ponnuraj K, Jedrzejas MJ. Mechanism of hyaluronan binding and degradation: structure of Streptococcus pneumoniae hyaluronate lyase in complex with hyaluronic acid disaccharide at $1.7 \mathrm{~A}$ resolution. J Mol Biol. 2000 Jun 16;299(4):885-95.

35. Fransson L. Mammalian Glycosaminoglycans. In: Aspinall G, editor. The Polysaccharides. St Louis, Missouri, USA: Academic Press, Inc.; 1985. p. 337-51.

36. Scott JE. Secondary structures in hyaluronan solutions: chemical and biological implications. Ciba Found Symp. 1989;143:6-15; discussion 20, 281-5.

37. Prieto JG, Pulido MM, Zapico J, Molina AJ, Gimeno M, Coronel P, et al. Comparative study of hyaluronic derivatives: rheological behaviour, mechanical and chemical degradation. Int J Biol Macromol. 2005 Mar;35(1-2):63-9.

38. Watanabe H, Yamada Y, Kimata K. Roles of aggrecan, a large chondroitin sulfate proteoglycan, in cartilage structure and function. $J$ Biochem. 1998 Oct;124(4):687-93.

39. Moreland LW. Intra-articular hyaluronan (hyaluronic acid) and hylans for the treatment of osteoarthritis: mechanisms of action. Arthritis Res Ther. 2003;5(2):54-67.

40. Itano N, Kimata K. Mammalian hyaluronan synthases. IUBMB Life. 2002 Oct;54(4):195-9.

41. Schulz T, Schumacher U, Prehm P. Hyaluronan export by the ABC transporter MRP5 and its modulation by intracellular cGMP. J Biol Chem. 2007 Jul 20;282(29):20999-1004. 
42. Nakazawa H, Yoshihara S, Kudo D, Morohashi H, Kakizaki I, Kon A, et al. 4-methylumbelliferone, a hyaluronan synthase suppressor, enhances the anticancer activity of gemcitabine in human pancreatic cancer cells. Cancer Chemother Pharmacol. 2006 Jan;57(2):165-70.

43. Milas M, Rinaudo M, Roure I, Al-Assaf S, Phillips GO, Williams PA. Comparative rheological behavior of hyaluronan from bacterial and animal sources with cross-linked hyaluronan (hylan) in aqueous solution. Biopolymers. 2001 Oct 5;59(4):191-204.

44. Nishimura M, Segami N, Kaneyama K, Suzuki T, Miyamaru M. Proinflammatory cytokines and arthroscopic findings of patients with internal derangement and osteoarthritis of the temporomandibular joint. Br J Oral Maxillofac Surg. 2002 Feb;40(1):68-71.

45. Kreil G. Hyaluronidases--a group of neglected enzymes. Protein Sci. 1995 Sep;4(9):1666-9.

46. Sato J, Segami N, Kaneyama K, Mashiyama Y, Fujimura K, Yoshitake $Y$. Vascular endothelial growth factor concentrations in synovial fluids of patients with symptomatic internal derangement of the temporomandibular joint. J Oral Pathol Med. 2005 Mar;34(3):170-7.

47. Urban JP. The chondrocyte: a cell under pressure. $\mathrm{Br} \mathrm{J}$ Rheumatol. 1994 Oct;33(10):901-8.

48. Tanimoto K, Kitamura R, Tanne Y, Kamiya T, Kunimatsu R, Yoshioka $M$, et al. Modulation of hyaluronan catabolism in chondrocytes by mechanical stimuli. J Biomed Mater Res A. 2009 Apr;93(1):373-80.

49. Balazs EA. The physical properties of synovial fluid and the special role of hyaluronic acid. In: Helfet $A$, editor. Disorders of the knee. Philadelphia: T. B. Lippincott Company; 1974. p. 63-75. 
50. Gomis A, Miralles A, Schmidt RF, Belmonte C. Intra-articular injections of hyaluronan solutions of different elastoviscosity reduce nociceptive nerve activity in a model of osteoarthritic knee joint of the guinea pig. Osteoarthritis Cartilage. 2009 Jun;17(6):798-804.

51. Akmal M, Singh A, Anand A, Kesani A, Aslam N, Goodship A, et al. The effects of hyaluronic acid on articular chondrocytes. $J$ Bone Joint Surg Br. 2005 Aug;87(8):1143-9.

52. Balazs EA, Denlinger JL. Clinical uses of hyaluronan. Ciba Found Symp. 1989;143:265-75; discussion 75-80, 81-5.

53. Comper WD, Laurent TC. Physiological function of connective tissue polysaccharides. Physiol Rev. 1978 Jan;58(1):255-315.

54. Turley EA, Noble PW, Bourguignon LY. Signaling properties of hyaluronan receptors. J Biol Chem. 2002 Feb 15;277(7):4589-92.

55. Camenisch TD, Spicer AP, Brehm-Gibson T, Biesterfeldt J, Augustine ML, Calabro A, Jr., et al. Disruption of hyaluronan synthase-2 abrogates normal cardiac morphogenesis and hyaluronan-mediated transformation of epithelium to mesenchyme. J Clin Invest. 2000 Aug;106(3):349-60.

56. Kosaki R, Watanabe K, Yamaguchi Y. Overproduction of hyaluronan by expression of the hyaluronan synthase Has2 enhances anchorageindependent growth and tumorigenicity. Cancer Res. 1999 Mar $1 ; 59(5): 1141-5$.

57. Hardingham TE, Fosang AJ. Proteoglycans: many forms and many functions. FASEB J. 1992 Feb 1;6(3):861-70. 
58. Toole BP. Hyaluronan in morphogenesis. J Intern Med. 1997 Jul;242(1):35-40.

59. Ahrens T, Assmann V, Fieber C, Termeer C, Herrlich P, Hofmann M, et al. CD44 is the principal mediator of hyaluronic-acid-induced melanoma cell proliferation. J Invest Dermatol. 2001 Jan;116(1):93101.

60. Noble PW. Hyaluronan and its catabolic products in tissue injury and repair. Matrix Biol. 2002 Jan;21(1):25-9.

61. Karjalainen JM, Tammi RH, Tammi MI, Eskelinen MJ, Agren UM, Parkkinen JJ, et al. Reduced level of CD44 and hyaluronan associated with unfavorable prognosis in clinical stage I cutaneous melanoma. Am J Pathol. 2000 Sep;157(3):957-65.

62. Tzircotis G, Thorne RF, Isacke CM. Chemotaxis towards hyaluronan is dependent on CD44 expression and modulated by cell type variation in CD44-hyaluronan binding. J Cell Sci. 2005 Nov 1;118(Pt 21):511928.

63. Hall CL, Lange LA, Prober DA, Zhang S, Turley EA. pp60(c-src) is required for cell locomotion regulated by the hyaluronanreceptor RHAMM. Oncogene. 1996 Nov 21;13(10):2213-24.

64. Park JB, Kwak HJ, Lee SH. Role of hyaluronan in glioma invasion. Cell Adh Migr. 2008 Jul-Sep;2(3):202-7.

65. Fieber C, Plug R, Sleeman J, Dall P, Ponta H, Hofmann M. Characterisation of the murine gene encoding the intracellular hyaluronan receptor IHABP (RHAMM). Gene. 1999 Jan 8;226(1):4150. 
66. McKee CM, Penno MB, Cowman M, Burdick MD, Strieter RM, Bao C, et al. Hyaluronan (HA) fragments induce chemokine gene expression in alveolar macrophages. The role of HA size and CD44. J Clin Invest. 1996 Nov 15;98(10):2403-13.

67. Oertli B, Fan X, Wuthrich RP. Characterization of CD44-mediated hyaluronan binding by renal tubular epithelial cells. Nephrol Dial Transplant. 1998 Feb;13(2):271-8.

68. Chen WY, Abatangelo G. Functions of hyaluronan in wound repair. Wound Repair Regen. 1999 Mar-Apr;7(2):79-89.

69. Aigner T, Kim HA. Apoptosis and cellular vitality: issues in osteoarthritic cartilage degeneration. Arthritis Rheum. 2002 Aug;46(8):1986-96.

70. Wyllie $\mathrm{AH}$, Kerr JF, Currie AR. Cell death: the significance of apoptosis. Int Rev Cytol. 1980;68:251-306.

71. Edinger AL, Thompson CB. Death by design: apoptosis, necrosis and autophagy. Curr Opin Cell Biol. 2004 Dec;16(6):663-9.

72. Nishida K, Otsu K. Cell death in heart failure. Circ J. 2008;72 Suppl A:A17-21.

73. Lotz M, Hashimoto S, Kuhn K. Mechanisms of chondrocyte apoptosis. Osteoarthritis Cartilage. 1999 Jul;7(4):389-91.

74. Hashimoto S, Ochs RL, Komiya S, Lotz M. Linkage of chondrocyte apoptosis and cartilage degradation in human osteoarthritis. Arthritis Rheum. 1998 Sep;41(9):1632-8. 
75. Hashimoto S, Ochs RL, Rosen F, Quach J, McCabe G, Solan J, et al. Chondrocyte-derived apoptotic bodies and calcification of articular cartilage. Proc Natl Acad Sci U S A. 1998 Mar 17;95(6):3094-9.

76. Schmitz JP, Dean DD, Schwartz Z, Cochran DL, Grant GM, Klebe RJ, et al. Chondrocyte cultures express matrix metalloproteinase mRNA and immunoreactive protein; stromelysin-1 and $72 \mathrm{kDa}$ gelatinase are localized in extracellular matrix vesicles. J Cell Biochem. 1996 Jun $1 ; 61(3): 375-91$.

77. Ishizaki Y, Burne JF, Raff MC. Autocrine signals enable chondrocytes to survive in culture. J Cell Biol. 1994 Aug;126(4):1069-77.

78. Kuhn K, Lotz M. Regulation of CD95 (Fas/APO-1)-induced apoptosis in human chondrocytes. Arthritis Rheum. 2001 Jul;44(7):1644-53.

79. Blanco FJ, Ochs RL, Schwarz H, Lotz M. Chondrocyte apoptosis induced by nitric oxide. Am J Pathol. 1995 Jan;146(1):75-85.

80. Borge L, Demignot S, Adolphe M. Type II transglutaminase expression in rabbit articular chondrocytes in culture: relation with cell differentiation, cell growth, cell adhesion and cell apoptosis. Biochim Biophys Acta. 1996 Jun 13;1312(2):117-24.

81. Adams CS, Horton WE, Jr. Chondrocyte apoptosis increases with age in the articular cartilage of adult animals. Anat Rec. 1998 Apr;250(4):418-25.

82. Werb Z. ECM and cell surface proteolysis: regulating cellular ecology. Cell. 1997 Nov 14;91(4):439-42. 
83. Meredith GE, Pennartz CM, Groenewegen HJ. The cellular framework for chemical signalling in the nucleus accumbens. Prog Brain Res. 1993;99:3-24.

84. Yang C, Li SW, Helminen HJ, Khillan JS, Bao Y, Prockop DJ. Apoptosis of chondrocytes in transgenic mice lacking collagen II. Exp Cell Res. 1997 Sep 15;235(2):370-3.

85. Hashimoto S, Setareh M, Ochs RL, Lotz M. Fas/Fas ligand expression and induction of apoptosis in chondrocytes. Arthritis Rheum. 1997 Oct;40(10):1749-55.

86. Miwa M, Saura R, Hirata S, Hayashi Y, Mizuno K, Itoh H. Induction of apoptosis in bovine articular chondrocyte by prostaglandin $E(2)$ through cAMP-dependent pathway. Osteoarthritis Cartilage. 2000 Jan;8(1):17-24.

87. Loening AM, James IE, Levenston ME, Badger AM, Frank EH, Kurz B, et al. Injurious mechanical compression of bovine articular cartilage induces chondrocyte apoptosis. Arch Biochem Biophys. 2000 Sep 15;381(2):205-12.

88. D'Lima DD, Hashimoto S, Chen PC, Lotz MK, Colwell CW, Jr. Prevention of chondrocyte apoptosis. J Bone Joint Surg Am. 2001;83A Suppl 2(Pt 1):25-6.

89. McKinley TO, Borrelli J, Jr., D'Lima DD, Furman BD, Giannoudis PV. Basic science of intra-articular fractures and posttraumatic osteoarthritis. J Orthop Trauma. 2010 Sep;24(9):567-70.

90. Gelber AC, Hochberg MC, Mead LA, Wang NY, Wigley FM, Klag MJ. Joint injury in young adults and risk for subsequent knee and hip osteoarthritis. Ann Intern Med. 2000 Sep 5;133(5):321-8. 
91. Roos EM. Joint injury causes knee osteoarthritis in young adults. Curr Opin Rheumatol. 2005 Mar;17(2):195-200.

92. Lawrence JT, Birmingham J, Toth AP. Emerging Ideas: Prevention of Posttraumatic Arthritis Through Interleukin-1 and Tumor Necrosis Factor-alpha Inhibition. Clin Orthop Relat Res. 2010 Dec 16.

93. Teeny SM, Wiss DA. Open reduction and internal fixation of tibial plafond fractures. Variables contributing to poor results and complications. Clin Orthop Relat Res. 1993 Jul(292):108-17.

94. Volpin G, Dowd GS, Stein H, Bentley G. Degenerative arthritis after intra-articular fractures of the knee. Long-term results. J Bone Joint Surg Br. 1990 Jul;72(4):634-8.

95. Quinn TM, Allen RG, Schalet BJ, Perumbuli P, Hunziker EB. Matrix and cell injury due to sub-impact loading of adult bovine articular cartilage explants: effects of strain rate and peak stress. J Orthop Res. 2001 Mar;19(2):242-9.

96. Martin JA, McCabe D, Walter M, Buckwalter JA, McKinley TO. Nacetylcysteine inhibits post-impact chondrocyte death in osteochondral explants. J Bone Joint Surg Am. 2009 Aug;91(8):1890-7.

97. Diaz-Gallego L, Prieto JG, Coronel P, Gamazo LE, Gimeno M, Alvarez Al. Apoptosis and nitric oxide in an experimental model of osteoarthritis in rabbit after hyaluronic acid treatment. J Orthop Res. 2005 Nov;23(6):1370-6.

98. Hurtig M, Chubinskaya S, Dickey J, Rueger D. BMP-7 protects against progression of cartilage degeneration after impact injury. J Orthop Res. 2009 May;27(5):602-11. 
99. Reiff RBM. Reparo do defeito osteocondral no joelho de coelhos utilizando centrifugado de medula óssea autóloga [Tese]. São Paulo: Universidade de São Paulo; 2010.

100. Bussab WO, Morettin PA. Estatística Básica. São Paulo: Atual; 1987.

101. Teeple E, Elsaid KA, Jay GD, Zhang L, Badger GJ, Akelman M, et al. Effects of supplemental intra-articular lubricin and hyaluronic acid on the progression of posttraumatic arthritis in the anterior cruciate ligament-deficient rat knee. Am J Sports Med. 2011 Jan;39(1):164-72.

102. Pelletier JP, Jovanovic DV, Lascau-Coman V, Fernandes JC, Manning PT, Connor JR, et al. Selective inhibition of inducible nitric oxide synthase reduces progression of experimental osteoarthritis in vivo: possible link with the reduction in chondrocyte apoptosis and caspase 3 level. Arthritis Rheum. 2000 Jun;43(6):1290-9.

103. Kaplan LD, Lu Y, Snitzer J, Nemke B, Hao Z, Biro S, et al. The effect of early hyaluronic acid delivery on the development of an acute articular cartilage lesion in a sheep model. Am J Sports Med. 2009 Dec;37(12):2323-7.

104. Rundell SA, Baars DC, Phillips DM, Haut RC. The limitation of acute necrosis in retro-patellar cartilage after a severe blunt impact to the in vivo rabbit patello-femoral joint. J Orthop Res. 2005 Nov;23(6):1363-9.

105. Williams JM, Zhang J, Kang H, Ummadi V, Homandberg GA. The effects of hyaluronic acid on fibronectin fragment mediated cartilage chondrolysis in skeletally mature rabbits. Osteoarthritis Cartilage. 2003 Jan;11(1):44-9. 
106. Takahashi K, Hashimoto S, Kubo T, Hirasawa Y, Lotz M, Amiel D. Hyaluronan suppressed nitric oxide production in the meniscus and synovium of rabbit osteoarthritis model. J Orthop Res. 2001 May;19(3):500-3.

107. Higgins TF, Johnson BD. Effect of exogenous IGF-1 on chondrocyte apoptosis in a rabbit intraarticular osteotomy model. J Orthop Res. 2010 Jan;28(1):125-30.

108. Ozkan FU, Ozkan K, Ramadan S, Guven Z. Chondroprotective effect of $\mathrm{N}$-acetylglucosamine and hyaluronate in early stages of osteoarthritis--an experimental study in rabbits. Bull NYU Hosp Jt Dis. 2009;67(4):352-7.

109. Ottaviani RA, Wooley P, Song Z, Markel DC. Inflammatory and immunological responses to hyaluronan preparations. Study of a murine biocompatibility model. J Bone Joint Surg Am. 2007 Jan;89(1):148-57.

110. Namazi $H$. Botulinum toxin as a novel addition to anti-arthritis armamentarium: an experimental study in rabbits. Int Immunopharmacol. 2006 Nov;6(11):1743-7.

111. Wobig M, Bach G, Beks P, Dickhut A, Runzheimer J, Schwieger G, et al. The role of elastoviscosity in the efficacy of viscosupplementation for osteoarthritis of the knee: a comparison of hylan G-F 20 and a lower-molecular-weight hyaluronan. Clin Ther. 1999 Sep;21(9):154962.

112. Ghosh P, Guidolin D. Potential mechanism of action of intra-articular hyaluronan therapy in osteoarthritis: are the effects molecular weight dependent? Semin Arthritis Rheum. 2002 Aug;32(1):10-37. 
113. Grootveld M, Henderson EB, Farrell A, Blake DR, Parkes HG, Haycock P. Oxidative damage to hyaluronate and glucose in synovial fluid during exercise of the inflamed rheumatoid joint. Detection of abnormal low-molecular-mass metabolites by proton-n.m.r. spectroscopy. Biochem J. 1991 Jan 15;273(Pt 2):459-67.

114. Sato $H$, Takahashi $T$, Ide H, Fukushima $T$, Tabata $M$, Sekine $F$, et al. Antioxidant activity of synovial fluid, hyaluronic acid, and two subcomponents of hyaluronic acid. Synovial fluid scavenging effect is enhanced in rheumatoid arthritis patients. Arthritis Rheum. 1988 Jan;31(1):63-71.

115. Lohmander LS, Atley LM, Pietka TA, Eyre DR. The release of crosslinked peptides from type II collagen into human synovial fluid is increased soon after joint injury and in osteoarthritis. Arthritis Rheum. 2003 Nov;48(11):3130-9.

116. Lohmander LS, Dahlberg L, Ryd L, Heinegard D. Increased levels of proteoglycan fragments in knee joint fluid after injury. Arthritis Rheum. 1989 Nov;32(11):1434-42.

117. Dang AC, Kim HT. Chondrocyte apoptosis after simulated intraarticular fracture: a comparison of histologic detection methods. Clin Orthop Relat Res. 2009 Jul;467(7):1877-84.

118. Schmitz N, Laverty $\mathrm{S}$, Kraus VB, Aigner $\mathrm{T}$. Basic methods in histopathology of joint tissues. Osteoarthritis Cartilage. 2010 Oct;18 Suppl 3:S113-6. 